GA-A15509

UC-77

\title{
DISTRIBUTION OF STEADY STATE TEMPERATURES AND THERMOELASTIC STRESSES IN A CYLINDRICAL SHELL WITH INTERNAL HEAT GENERATION AND COOLED ON BOTH SIDES OR ONLY ON ONE SIDE
}

by

GILBERT B. MELESE d'HOSPITAL

Prepared under

Contract DE-AT03-76ET35300

for the San Francisco Operations Office

Department of Energy

DATE PUBLISHED: OCTOBER 1979

\section{GENERAL ATOMIC COMPANY}




\section{DISCLAIMER}

This report was prepared as an account of work sponsored by an agency of the United States Government. Neither the United States Government nor any agency Thereof, nor any of their employees, makes any warranty, express or implied, or assumes any legal liability or responsibility for the accuracy, completeness, or usefulness of any information, apparatus, product, or process disclosed, or represents that its use would not infringe privately owned rights. Reference herein to any specific commercial product, process, or service by trade name, trademark, manufacturer, or otherwise does not necessarily constitute or imply its endorsement, recommendation, or favoring by the United States Government or any agency thereof. The views and opinions of authors expressed herein do not necessarily state or reflect those of the United States Government or any agency thereof. 


\section{DISCLAIMER}

Portions of this document may be illegible in electronic image products. Images are produced from the best available original document. 
This report was prepared as an account of work sponsored by the United States Government. Neither the United States nor the Department of Energy, nor any of their employees, nor any of their contractors, subcontractors, or their employees, makes any warranty, express or implied, or assumes any legal liability or responsibility for the accuracy, completeness or usefulness of any information, apparatus, product or process disclosed, or represents that its use would not infringe privately owned rights.

\author{
Printed in the United States of America \\ Available from \\ National Technical Information Service \\ U.S. Department of Commerce \\ 5285 Port Royal Road \\ Springfield, Virginia 22161 \\ Price: Printed Copy $\$ 6.00$; Microfiche $\$ 3.00$
}


GA-A15509

UC-77

\section{DISTRIBUTION OF STEADY STATE TEMPERATURES AND THERMOELASTIC STRESSES IN A CYLINDRICAL SHELL WITH INTERNAL HEAT GENERATION AND COOLED ON BOTH SIDES OR ONLY ON ONE SIDE This book was prepared as an account of work sponsored by an agency of the United States Government.
Neither the United States Government nor any agency thereof, nor any of their employees, makes any
warranty, express or implieed, or assumes any legal liability or responsibility for the accuracy.
completeness, or usefulness of any information, apporatus. product, or process disclosed, or
represents that its use would not infringe privately owned rights. Reference herein to any specific
commercial product, process, or service by trade name, trademark, manufacturer, or otherwise, does
not necessarily constitute or imply its endorsement, recommendation, or favoring by the United
States Government or any agency thereof. The views and opinions of authors expressed herein do not
necessarily state or reflect those of the United States Government or any agency thereof. \\ by \\ $\checkmark$ GILBERT B. MELESE d'HOSPITAL}

Prepared under

Contract DE-AT03-76ET35300 for the San Francisco Operations Office

Department of Energy

GENERAL ATOMIC PROJECT 6400 DATE PUBLISHED: OCTOBER 1979

\section{GENERAL ATOMIC COMPANY}




\section{ABSTRACT}

General expressions for steady state temperatures and elastic thermal stress distributions are derived for a hollow fuel element cooled on both sides. The main simplifying assumptions consist of one dimensional heat transfer and a single medium. Dimensionless numerical results are plotted in the case of uniform internal heat generation and for constant thermal conductivity. Solid rods and flat plates are treated as special cases.

As could be expècted, cooling on both sides rather than on only one side, leads to significant reduction in maximum fuel temperature and thermal stresses for a given power density, or to a significant increase in power density for either given maximum temperature drop in the fuel or for maximum tensile thermal stress. Typically, for a rod diameter ratio of 2 , the power density could be increased by a factor of 3-4 without increasing the maximum stress.

Similarly, for the same power density, replacing internal cooling of a hollow fuel element by external cooling reduces the maximum fuel temperature drop by a factor of 1.5 and the average fuel temperature drop (or maximum tensile stress) by a factor of 2 , with the same maximum compressive stress (for a rod O.D./I.D. of 2). 
TABLE OF CONTENTS

ABSTRACT ................................... i

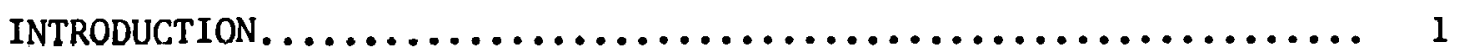

I. GENERAL DERIVATION OF TEMPERATURE DISTRIBUTION........... 1

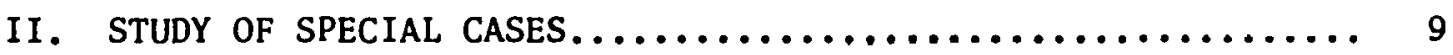

III. COMPARISON OF DIFFERENT WAYS OF COOLING FOR UNIFORM

POWER DENSITY.............................. 15

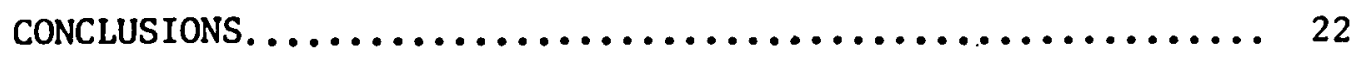

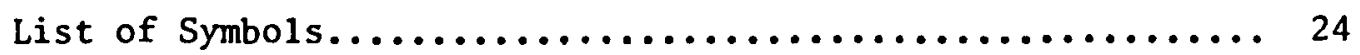

Table I: Dimensionless Temperatures and Stresses for

Various Types of Cooling........................ 26

Table II: Comparison of various types of Cooling ........ 27

APPENDIX A: Maximum and Average Fuel Temperatures for Uneven

Cooling on Both Sides and Uniform Power Density..... 28

APPENDIX B: Remarks about the Special Case of a Slab......... 32

APPENDIX C: Derivation of Elastic Thermal Stress Distributions.. 37

LIST OF FIGURES ............................... 51 


\section{INTRODUCTION}

Ways of cooling a hollow fuel element for steady state heat generation are assessed by comparing power density, maximum internal temperature, average and surface temperatures, and maximum tensile and compressive thermal stresses. The maximum tensile stress is proportional to the difference between average and surface fuel temperatures, while the maximum compressive stress is proportional to the difference between maximum and average temperatures.

Numerical values are derived in the case of uniform power density and constant thermal conductivity for the three cases of cooling on both sides, and internal or external cooling. The main simplifying assumptions are that of one dimensional (radial) temperature distribution, and a single medium with internal heat generation.

\section{General Derivation of the Temperature Distribution}

The one dimensional steady-state heat conduction equation for an infinitely long cylinder reads:

$$
\frac{1}{r} \frac{d}{d r}\left(K r \frac{d T}{d r}\right)+H(r)=0
$$

(see. list of symbols).

The two boundary conditions correspond to given heat transfer coefficients $\left(h_{i}\right)$ at the inner and outer surfaces of the cylindrical shell. The heat flux per unit length for the inner and outer boundary are, respectively: 


$$
\begin{aligned}
& Q_{1}=2 \pi \quad r_{1} h_{1} T\left(r_{1}\right)=2 \pi\left(K r \frac{d T}{d r}\right) r_{1} \\
& Q_{2}=2 \pi \quad r_{2} h_{2} T\left(r_{2}\right)=-2 \pi\left(K r \frac{d T}{d r}\right) r_{2}
\end{aligned}
$$

where the bulk coolant temperatures are assumed to be the same on both sides and is taken as reference temperature.

Notice that the sum of the two heat fluxes correspond to the linear heat generation in the fuel, or:

$$
Q_{1}+Q_{2}=Q=\pi\left(r_{2}{ }^{2}-r_{1}^{2}\right) H_{a v}=2 \pi \int_{r_{1}}^{r_{2}} r \mathrm{Hdr}
$$

The following relationship may be derived between the surface temperatures, $T\left(r_{1}\right), T\left(r_{2}\right)$ and the linear heat generation $Q$ :

$$
\frac{Q}{2 \pi}=r_{1} h_{1} T\left(r_{1}\right)+r_{2} H_{2} T\left(r_{2}\right)
$$

A first integration of equation (1) yields:

$$
K \frac{d T}{d r}=-\frac{1}{r} \int_{r_{1}}^{r} r^{\prime} H d r^{-}+\frac{r_{1}}{r} h_{1} T\left(r_{1}\right)
$$

(using the lst boundary condition) while a second integration gives:

$$
T(r)=T\left(r_{2}\right)+\frac{r_{1} h_{1}}{K} T\left(r_{1}\right) \ln \left(\frac{r}{r_{2}}\right)+\frac{1}{k} \int_{r}^{r_{2}} \frac{d r^{\prime}}{r^{\prime}} \int_{r_{1}}^{r} r^{\cdots} H d r^{\cdots}
$$

Using integration by parts in the second integral, the temperature distribution reads:

$T(r)-T\left(r_{2}\right)=B_{1} T\left(r_{1}\right) \ln \left(\frac{r}{r_{2}}\right)+\frac{Q}{2 K} \ln r_{2}-\frac{\ln r}{K} \int_{r_{1}}^{r} r^{\prime} H d r^{\prime}-\frac{1}{K} \int_{r}^{r} r^{\prime} \ln r^{\prime} H d r^{\prime}$ 
with the help of Eq. 4 and introducing the Biot number $B=r h / K$ (ratio of surface heat transfer to conduction in the fuel). Similar results would be obtained for variable thermal conductivity by using the conductivity integral $\int_{\mathrm{T}_{2}}^{\mathrm{T}} \mathrm{KdT}$ instead of $\mathrm{K}\left(\mathrm{T}-\mathrm{T}_{2}\right)$.

The difference between surface temperatures may then be written:

$$
T\left(r_{1}\right)-T\left(r_{2}\right)=B_{1} T\left(r_{1}\right) \ln \left(\frac{r_{1}}{r_{2}}\right)+\frac{Q}{2 \pi K} \ln r_{2}-\frac{1}{K} \int_{r_{1}}^{r_{2}} r^{\prime} \ell n r^{\prime} H d r^{\prime}
$$

Since Eq. (5) also gives the following relationship between surface temperatures:

$$
B_{1} T\left(r_{1}\right)+B_{2} T\left(r_{2}\right)=Q / 2 \pi K
$$

the surface temperatures may now be derived from the two previous equations:

$$
\begin{aligned}
& \frac{1 / B_{2}+\ln r_{2}-\frac{2 \pi}{Q} \int_{r_{1}}^{r_{2}} r \ln r H d r}{1+B_{1} / B_{2}+B_{1} \ln \left(r_{2} / r_{1}\right)} \\
& \frac{1 / B_{1}-\ln r_{1}+\frac{2 \pi}{Q} \int_{r_{1}}^{r} r \operatorname{lnr} H d r}{1+B_{2} / B_{1}+B_{2} \ln \left(r_{2} / r_{1}\right)}
\end{aligned}
$$

The ratio of heat fluxes is simply:

$$
\frac{Q_{1}}{Q_{2}}=\frac{B_{1} T\left(r_{1}\right)}{B_{2} T\left(r_{2}\right)}=\frac{1 / B_{2}+\ell n r_{2}-\frac{2 \pi}{Q} \int_{r_{1}}^{r_{2}^{2} r} \operatorname{lnr} H d r}{1 / B_{1}-\ell n r_{1}+\frac{2 \pi}{Q} \int_{r_{1}}^{r_{2}} r \operatorname{lnr} \mathrm{Hdr}}
$$


while the difference between surface temperatures reads:

$$
\frac{2 \pi K}{Q}\left\{T\left(r_{1}\right)-T\left(r_{2}\right)\right\}=\frac{\ell n r_{2} / B_{1}+\ell n r_{1} / B_{2}-\left(\frac{1}{B_{1}}+\frac{1}{B_{2}}\right) \frac{2 \pi}{Q} \int_{r_{1}}^{r} r \ln H \mathrm{Hdr}}{1 / B_{1}+1 / B_{2}+\ln \left(r_{2} / r_{1}\right)}
$$

Using Eq. (11) and (12) for the surface temperatures, the temperature distribution given by.Eq. (8) may be written:

$$
\begin{aligned}
\frac{2 \pi K}{Q} T(r) & =\frac{\left(1+B_{2} \ell n r_{2}\right)\left(1-B_{1} \ln r_{1}+B_{1} I\right)+B_{1} \operatorname{lnr} \cdot\left(1+B_{2} \ln r_{2}-B_{2} I\right)}{B_{1}+B_{2}+B_{1} B_{2} \ln \left(r_{2} / r_{1}\right)} \\
& -\frac{2 \pi}{Q} \ln r \int_{r_{1}}^{r} r^{-H d r}-\frac{2 \pi}{Q} \int_{r}^{r} r^{\prime} \ln r^{\prime} H_{d r}^{-} .
\end{aligned}
$$

where we have defined the integral: $I=\frac{2 \pi}{Q} \int_{r_{1}}^{r} r$ ln $r$ Hdr

We can now find the maximum fuel temperature $\left(T_{m}\right)$ and its location $\left(r_{m}\right)$. Using Eq. (6), we find the relationship:

$$
\int_{r_{1}}^{r} r^{-} H d r^{-}=r_{1} h_{1} T\left(r_{1}\right)
$$

Using expression (11) for $T\left(r_{1}\right), r_{m}$ is given by the equation:

$$
\frac{2 \pi}{\mathrm{Q}} \int_{\mathrm{r}_{1}}^{\mathrm{r}} \mathrm{r} \mathrm{Hdr}=\frac{1 / \mathrm{B}_{2}+\ln \mathrm{r}_{2}-\mathrm{I}}{1 / \mathrm{B}_{1}+1 / \mathrm{B}_{2}+\ln \left(\mathrm{r}_{2} / \mathrm{r}_{1}\right)}
$$


The corresponding relationship for the maximum temperature may then be written:

$\frac{2 \pi K}{Q} T_{m}=\frac{\left(\frac{1}{B_{2}}+\ln r_{2}\right)\left(\frac{1}{B_{1}}-\ln r_{1}+I\right)}{1 / B_{1}+1 / B_{2}+\ln \left(r_{2} / r_{1}\right)}-\frac{2 \pi}{Q} \int_{r_{m}}^{r_{2}} r^{\prime} \ln r^{\prime} H\left(r^{\prime}\right) d r^{\prime}$

Finally, the average fuel temperature is obtained by further integration of Equation (15), since, by definition

$$
T_{a v}=\frac{2}{r_{2}^{2}-r_{1}^{2}} \int_{r_{1}}^{r_{2}} r T(r) d r
$$

After integration by parts and simplifications, one finds:

$$
\begin{aligned}
\frac{2 \pi K}{Q} T_{a v} & =-\frac{\pi}{Q\left(r_{2}^{2}-r_{1}^{2}\right)} \int_{r_{1}^{0}}^{r_{2}} r^{3} H d r \\
& +\frac{\frac{1}{4}\left(\ell r_{2}^{2}-t \ell n r_{1}^{2}\right)+\frac{t-1}{B_{1} B_{2}}+\frac{1-t \operatorname{lng}_{1}^{2}}{2 B_{2}}+\frac{t \operatorname{lng}_{2}^{2}}{2 B_{1}}+\left(\frac{t-1}{2}+\frac{t}{B_{2}}+\frac{1}{B_{1}}\right) I}{(t-1)\left(\frac{1}{B_{1}}+\frac{1}{B_{2}}+\frac{1}{2} \ln t\right)}
\end{aligned}
$$

where we have used for simplification $t=r_{2}^{2} / r_{1}^{2}$.

\section{Dimensionless Considerations:}

By dimensional reasoning the ratio of heat fluxes and the dimensionless temperatures, $\frac{2 \pi K T}{Q}$, should only be functions of dimensionless parameters, namely the Biot numbers $\left(B_{1}, B_{2}\right)$, the ratio of fuel radii $\left(r_{2} / r_{1}\right)$ and the power distribution. These results are easily found by introducing $\ln \left(r / r_{2}\right)$ 
into the integral $I$ and yields the following relations after defining a (dimensionless) new integral

$J=-\frac{2 \pi}{Q} \int_{r_{1}}^{r_{2}} r \ln \left(\frac{\dot{r}}{r_{2}}\right) H(r) d r=\ln r_{2}-I=-\frac{1}{2\left(1-R_{1}\right)} \int_{R_{1}}^{l} \ln \frac{R}{-\frac{H}{H_{a v}}} d^{-}$

with

$$
\begin{aligned}
& \mathrm{R}=\mathrm{r}^{2} / \mathrm{r}_{2}{ }^{2} \text { and } \mathrm{R}_{1}=\mathrm{r}_{1}{ }^{2} / \mathrm{r}_{2}{ }^{2} \text {. } \\
& \text { Recal1 that } Q=2 \pi \int_{r_{1}}^{\mathrm{r}} r \mathrm{Hdr}=\pi\left(\mathrm{r}_{2}{ }^{2}-\mathrm{r}_{1}{ }^{2}\right) \mathrm{H}_{\mathrm{av}} \text {. } \\
& \theta_{1}=\frac{4 \pi K}{Q} T\left(r_{1}\right)=\frac{2 J+2 / B_{2}}{1+\frac{B_{1}}{B_{2}}+-\frac{B_{1}}{2} \ln R_{1}} \\
& \theta_{2}=\frac{4 \pi K}{Q} T\left(r_{2}\right)=\frac{-\ln R_{1}-2 J+2 / B_{1}}{1+B_{2} / B_{1}-\frac{B_{2}}{2} \ln R_{1}} . \\
& \theta_{1}-\theta_{2}=\frac{4 \pi K}{Q}\left\{T\left(r_{1}\right)-T\left(r_{2}\right)\right\}=\frac{2\left(\frac{1}{B_{1}}+\frac{1}{B_{2}}\right) J+\frac{1}{B_{2}} \ln R_{1}}{1 / B_{1}+1 / B_{2}-\frac{1}{2} \ln R_{1}} \\
& \frac{Q_{1}}{Q_{2}}=\frac{J+1 / B_{2}}{-\frac{1}{2} \ln R_{1}+1 / B_{1}-J}
\end{aligned}
$$


Similarly, the location of the maximum surface temperature $\left(R_{m}=r_{m}{ }^{2} / r_{2}{ }^{2}\right)$ is given by the relation:

$\frac{1}{1-R_{1}} \int_{R_{1}}^{\mathrm{R}} \frac{\mathrm{H}}{\mathrm{H}_{\mathrm{av}}} \mathrm{dR} \mathrm{R}^{\prime}=\frac{2 \pi}{\mathrm{Q}} \int_{\mathrm{r}_{1}}^{\mathrm{r}} \mathrm{r}^{\prime} \mathrm{Hdr^{ \prime }}=\frac{1 / \mathrm{B}_{2}+\mathrm{J}}{1 / \mathrm{B}_{1}+1 / \mathrm{B}_{2}-\frac{1}{2} \ln \mathrm{R}_{1}}=\left(\frac{\mathrm{Q}_{1}}{\mathrm{Q}}\right)$

while the maximum temperature may be written:"

$\theta_{m}=\frac{4 \pi K}{Q} T_{m}=-\frac{1}{1-R_{1}} \int_{R_{m}}^{1} \ln R^{-} \frac{H}{H_{a v}} d^{-}+\frac{-\ell n R_{1}-2 J+2 / B_{1}}{1+B_{2} / B_{1}-\frac{2}{2} \ell n R_{1}}$

or simply,

$$
\theta_{m}-\theta_{2}=-\frac{1}{1-R_{1}} \int_{R_{m}^{\prime}}^{1} \ell n R^{-} \frac{H}{H_{a v}} d R^{-}
$$

Finally, the average fuel temperature may be written:

$$
\frac{4 \pi \mathrm{K}}{\mathrm{Q}}\left(\mathrm{T}_{\mathrm{av}}-\mathrm{T}_{2}\right)=\theta_{\mathrm{av}}-\theta_{2}=-\left(\Theta_{1}-\Theta_{2}\right)\left(\frac{1}{\ln \mathrm{R}_{1}}+\frac{\mathrm{R}_{1}}{1-\mathrm{R}_{1}}\right)+\frac{1}{1-\mathrm{R}_{1}}+\frac{2 \mathrm{~J}}{\ln \mathrm{R}_{1}}-2 \mathrm{~L}
$$

with the dimensionless integral,



and $\left(\theta_{1}-\theta_{2}\right)$ given by Eq. (25) . 
Finally, the temperature distribution given by Eq. (15) could be written in dimensionless form:

$\theta-\theta_{2}=\left(\theta_{1}-\theta_{2}\right) \frac{\operatorname{lnR}}{\ln R_{1}}-\frac{2 J}{\ln R_{1}} \ln \left(\frac{R}{R_{1}}\right)+\frac{1}{1-R_{1}} \int_{R_{1}}^{R} \frac{H}{H_{a v}} \ln \left(\frac{R^{\prime}}{R}\right) d R^{\prime}$

with $\mathrm{J}$ given by eq. (22):

$$
J=-\frac{1}{2\left(1-R_{1}\right)} \int_{R_{1}}^{1} \frac{H}{H_{a v}} \text { ln } R^{-} d^{-}
$$


II. Study of Special Cases

Since the Biot number (B) is defined as the ratio of heat convection to conduction in the fuel, a zero value of $B$ will correspond to an insulated surface, while a zero value of $1 / B$ will mean a given surface temperature (since the surface temperature is the same as the bulk coolant temperature). We shall therefore consider the following cases:
a) $B_{1}=0$ :
external cooling only $\left(B_{2} \neq 0\right)$
b) $\mathrm{B}_{2}=0$ :
internal cooling only $\left(B_{1} \neq 0\right)$
c) $\frac{1}{\mathrm{~B}_{1}}=\frac{1}{\mathrm{~B}_{2}}=0$ :
same given value of surface temperature.

d) We could also study the condition when the surface temperatures are equal. Equation (14) yields the following relationship (when $1 / B_{1}$ and $1 / B_{2}$ are not both zero) and $B_{1} B_{2} \neq 0$.

$$
B_{2} / B_{1}=\frac{\ln \left(r_{2} / r_{1}\right)}{J}-1
$$

which indicates the ratios of heat transfer coefficients required to yield the same surface temperatures for a given radial power distribution in the fue1:

$$
\frac{h_{2}}{h_{1}}=-\frac{r_{1}}{r_{2}}\left\{1+\frac{\ln \left(r_{2} / r_{1}\right) \int_{r_{1}}^{r_{2}} r H(r) d r}{\int_{r_{1}}^{r_{2}} r \ln \left(r / r_{2}\right) H(r) d r}\right\}
$$

For instance, for a uniform power distribution $\left(\mathrm{H}_{\mathrm{av}}\right)$ 


$$
\int_{r_{1}}^{r_{2}} r \ln \left(r / r_{2}\right) H(r) d r=-\frac{r_{2}{ }^{2}-r_{1}{ }^{2}}{4} H_{a v}\left\{1-\frac{\ln \left(r_{2}{ }^{2} / r_{1}{ }^{2}\right)}{r_{2}{ }^{2} / r_{1}{ }^{2}-1}\right\}
$$

and the expression for $\mathrm{J}$ now reads simply

$$
J=\frac{1}{2}\left[1-\frac{\ln \left(\mathrm{r}_{2}{ }^{2} / \mathrm{r}_{1}{ }^{2}\right)}{\mathrm{r}_{2}{ }^{2} / \mathrm{r}_{1}{ }^{2}-1}\right]=\frac{1}{2}\left(1+\frac{\ln \mathrm{R}_{1}}{1 / \mathrm{R}_{1}-1}\right)
$$

Equation (33) becomes:

$$
\frac{h_{1}}{h_{2}}=\frac{r_{2}}{r_{1}} \frac{1-\frac{\ln \left(r_{2}{ }^{2} / r_{1}{ }^{2}\right)}{r_{2}{ }^{2} / r_{1}{ }^{2}-1}}{\frac{r_{2}{ }^{2} / r_{1}{ }^{2}}{r_{2}{ }^{2} / r_{1}{ }^{2}-1} \ln \left(\frac{r_{2}{ }^{2}}{r_{1}{ }^{2}}\right)-1}=-\frac{1+\frac{\ell n R_{1}}{1 / R_{1}-1}}{\sqrt{R_{1}\left(1+\frac{\ell n R_{1}}{1-R_{1}}\right)}}
$$

(In this case, we find as expected $\frac{Q_{1}}{Q_{2}}=\frac{B_{1}}{B_{2}}=\frac{h_{1} r_{1}}{h_{2} r_{2}}$; See Eq. 2 and 3) Let us a1so notice that expression (31) becomes simpler for uniform power density:

$$
\mathrm{L}=\frac{\pi}{\mathrm{Q}\left(\mathrm{r}_{2}{ }^{2}-\mathrm{r}_{1}{ }^{2}\right)} \int_{\mathrm{r}_{1}}^{\mathrm{r}} \mathrm{r}^{3} \mathrm{Hdr}=\frac{\mathrm{r}_{2}{ }^{2}+\mathrm{r}_{1}{ }^{2}}{4\left(\mathrm{r}_{2}{ }^{2}-\mathrm{r}_{1}{ }^{2}\right)}=\frac{1}{4} \frac{1+\mathrm{R}_{1}}{1-\mathrm{R}_{1}}
$$

\section{a) External Cooling Only}

In that case, the maximum fuel temperature occurs at the inner boundary:

$$
T_{m}=T\left(r_{1}\right) \text {, since } B_{1}=0 \text {. }
$$


and one finds simply:

$$
\begin{aligned}
& \frac{2 \pi K}{Q} T\left(r_{1}\right)=J+1 / B_{2} \\
& \frac{2 \pi K}{Q} T\left(r_{2}\right)=1 / B_{2} \\
& \theta_{m}-\theta_{2}=\frac{4 \pi K}{Q}\left\{T_{m}-T\left(r_{2}\right)\right\}=2 J \\
& \frac{2 \pi \mathrm{K}}{\mathrm{Q}} \mathrm{T}_{\mathrm{av}}=\frac{1}{\mathrm{~B}_{2}}+\frac{1 / 2}{1-\mathrm{r}_{1}^{2} / \mathrm{r}_{2}{ }^{2}}-\mathrm{L}-\frac{\mathrm{J}}{\mathrm{r}_{2}^{2} / \mathrm{r}_{1}{ }^{2}-1} \\
& \Theta_{\mathrm{av}^{-}{ }_{2}}=\frac{4 \pi \mathrm{K}}{\mathrm{Q}}\left\{\mathrm{T}_{\mathrm{av}}-\mathrm{T}\left(\mathrm{r}_{2}\right)\right\}=\frac{1}{1-\mathrm{R}_{1}}-2 \mathrm{~L}-\frac{2 \mathrm{~J}}{1 / \mathrm{R}_{1}-1} \\
& \Theta_{\mathrm{m}}-\Theta_{\mathrm{av}}=\frac{4 \pi \mathrm{K}}{\mathrm{Q}}\left\{\mathrm{T}_{\mathrm{m}}-\mathrm{T}_{\mathrm{av}}\right\}=2 \mathrm{~L}+\frac{2 \mathrm{~J}-1}{\mathrm{l}-\mathrm{R}_{1}}
\end{aligned}
$$

The maximum temperature drop in the fuel is given by Eq. (39), while the maximum thermal stresses (tensile and compressive) are given by Eq. (41) and (42) respectively.

b) Interna1 Cooling Only

With $B_{2}=0$, the following expressions are derived, with $T_{m}=T\left(r_{2}\right)$ :

$$
\frac{2 K}{Q} T\left(r_{2}\right)=\ln \left(r_{2} / r_{1}\right)-J+1 / B_{1}
$$




$$
\begin{aligned}
& \frac{2 \pi K}{Q} \quad T\left(r_{1}\right)=1 / B_{1} \\
& \Theta_{m}-\Theta_{1}=\frac{4 \pi K}{Q}\left\{T_{m}-T\left(r_{1}\right)\right\}=-2 J-\ell n_{1} \\
& \frac{2 \pi K}{Q} T_{a v}=-L+\frac{1}{B_{1}}+\frac{1+\frac{2 r_{2}^{2}}{r_{1}^{2}} \ln \left(\frac{r_{2}}{r_{1}}\right)}{2\left(r_{2}{ }^{2} / r_{1}{ }^{2}-1\right)}-\frac{J}{1-r_{1}{ }^{2} / r_{2}{ }^{2}} \\
& \Theta_{a v}{ }^{-\theta_{1}}=\frac{4 \pi K}{Q}\left\{T_{a v}-T\left(r_{1}\right)\right\}=-2 L-\frac{2 J+\ln R_{1}-R_{1}}{1-R_{1}} \\
& \Theta_{\mathrm{m}}-\Theta_{\mathrm{av}}=\frac{4 \pi \mathrm{K}}{\mathrm{Q}}\left\{\mathrm{T}_{\mathrm{m}}-\mathrm{T}_{\mathrm{av}}\right\}=2 \mathrm{~L}+\frac{2 \mathrm{~J}-1+\mathrm{lnR}_{1}}{\overline{\mathrm{R}}_{1}-1}
\end{aligned}
$$

Maximum temperature drop and thermal stresses are given by Eq. (45),

(47) and (48) respectively.

c) Same Surface Temperatures:

The required relationship between the Biot numbers is given by Eq. (33) :

$$
\frac{\mathrm{B}_{2}}{\mathrm{~B}_{1}}=\frac{\ln \left(\mathrm{r}_{2} / \mathrm{r}_{1}\right)}{\mathrm{J}}-1
$$

and the ratio of heat fluxes is independent of the Biot number:

$$
\frac{\mathrm{Q}_{2}}{\mathrm{Q}_{1}}=\frac{\mathrm{B}_{2}}{\mathrm{~B}_{1}}=\frac{\ln \left(\mathrm{r}_{2} / \mathrm{r}_{1}\right)}{\mathrm{J}}-1=-1-\frac{\ln \mathrm{R}_{1}}{2 \mathrm{~J}}
$$


The surface Temperature $\left(\mathrm{T}_{\mathrm{S}}\right)$ now reads simply:

$$
\theta_{s}=\frac{4 \pi K}{Q} \quad T_{s}=\frac{2}{B_{2}}\left\{1+2 J / \ell R_{1}\right\}=\frac{-4 J}{B_{1} \ell n R R_{1}}
$$

Eq. (27) for location of the maximum temperature becomes independent of the Biot number since the two surface temperatures are equal.

$$
\frac{2 \pi}{Q} \int_{r_{1}}^{r} r H d r=\frac{-2 . J}{\ln R_{1}}=\frac{1}{1-R_{1}} \int_{R_{1}}^{R_{m}^{m}} \frac{H}{H_{a v}} d^{-}
$$

with the difference between maximum and surface temperature still given by the relation (see Eq. 29)

$$
\mathrm{T}_{\mathrm{m}}-\mathrm{T}_{\mathrm{s}}=-\frac{1}{\mathrm{~K}} \int_{r_{\mathrm{m}}}^{\mathrm{r}_{2}} \mathrm{r} \ln \left(\mathrm{r} / \mathrm{r}_{2}\right) \mathrm{H}(\mathrm{r}) \mathrm{dr} \text {, or } \Theta_{\mathrm{m}}-\Theta_{\mathrm{s}}=-\frac{1}{1-\mathrm{R}_{1}} \int_{\mathrm{R}_{\mathrm{m}}}^{1} \ell_{n R^{-}} \frac{\mathrm{H}_{\mathrm{av}}}{\mathrm{H}_{\mathrm{av}}} \mathrm{dR}^{-}
$$

which is independent of the Biot number (since the location $r_{m}$ of the maximum temperature only depends on the power distribution and on the geometry, $r_{2} / r_{1}$ : see Eq. 22 defining $J$ ).

The average fuel temperature derived from Eq. (30) with condition (33) may be written:

$$
\theta_{\mathrm{av}}=\frac{4 \pi \mathrm{K}}{\mathrm{Q}} \mathrm{T}_{\mathrm{av}}=-2 \mathrm{~L}-\frac{4 \mathrm{~J}}{\mathrm{~B}_{1} \ln \mathrm{R}_{1}}+\frac{2 \mathrm{~J}}{\ln \mathrm{R}_{1}}+\frac{1}{1-\mathrm{R}_{1}}
$$

with L given by Eq. (31).

The difference between average and surface temperatures

$$
\Theta_{a v}-\Theta_{s}=\frac{4 \pi K}{Q}\left(T_{a v}-T_{s}\right)=-2 L+\frac{1}{1-R_{1}}+\frac{2 J}{\ln R_{1}}
$$


is now independent of Biot number as could be expected. (Notice that Eq. (49), (51), and (54) could be simply obtained by letting $\frac{1}{\mathrm{~B}_{1}}=\frac{1}{\mathrm{~B}_{2}}=0$ in Eq. (26), (27), and (30) ). Finally, the difference between maximum and average temperature which is obtained by combining Eq. (52) and (54) also becomes independent of the Biot number. Therefore the dimensionless maximum temperature drop in the fuel (Eq. 52) and the maximum thermal stresses only depend on the geometry and the radial power distribution when the surface temperature is the same on both sides of the fuel element. The same result obtains for the ratio of heat fluxes and the relative location of the maximum fuel temperature. (See Eq. 49 and 51). 
III. Comparison of Different Ways of Cooling for Uni form Power Density

Recall that in the case of uniform power density, integrals $\mathrm{J}$ and $\mathrm{L}$ are given by Eq. (34) and (36) respectively.

$$
\begin{aligned}
& J=\frac{1}{2}\left(1-\frac{\ln t^{2}}{t^{2}-1}\right)=\frac{1}{2}\left(1+\frac{\ln R_{1}}{1 / R_{1}-1}\right) \\
& L=\frac{t^{2}+1}{4\left(t^{2}-1\right)}=\frac{1}{4} \cdot \frac{1+R_{1}}{1-R_{1}} .
\end{aligned}
$$

where we have introduced the ratios $t=r_{2} / r_{1}$, and $R_{1}=\frac{r_{1}{ }^{2}}{r_{2}{ }^{2}}=1 / t^{2}$.

We shall now compute the three quantities of most interest, namely maximum temperature drop and thermal stresses, for the three special cases already considered: external cooling, internal cooling, and cooling on both sides with the same surface temperature. Let us therefore define the following dimensionless expressions, $T_{S}$ being the surface temperature of interest

$$
\begin{gathered}
\delta \mathrm{T}_{\mathrm{m}}=\frac{4 \pi \mathrm{K}}{\mathrm{Q}}\left(\mathrm{T}_{\mathrm{m}}-\mathrm{T}_{\mathrm{s}}\right) \\
\delta \mathrm{T}_{\mathrm{av}}=\frac{4 \pi \mathrm{K}}{\mathrm{Q}}\left(\mathrm{T}_{\mathrm{av}}-\mathrm{T}_{\mathrm{s}}\right) \\
\text { and } \quad \delta \mathrm{T}_{\mathrm{m}}-\delta \mathrm{T}_{\mathrm{av}}=\frac{4 \pi \mathrm{K}}{\mathrm{Q}}\left(\mathrm{T}_{\mathrm{m}}-\mathrm{T}_{\mathrm{av}}\right)
\end{gathered}
$$

Substitution of Eq. (55) and (56) into equation (37) through (54) yield expressions for those four quantities which only depend upon the ratio of radii $(t)$, and upon the Biot number. The Biot number dependence 
can be eliminated by introducing the quantity:

$$
S=\frac{4 \pi K}{Q} \quad B \quad T_{S}
$$

which only depend upon $t$. Therefore, we could write the maximum temperature as:

$$
\frac{4 \pi K}{Q} \quad T_{m}=\delta T_{m}+\frac{S}{B}
$$

where $\delta T_{m}$ and $S$ only depend upon $t$ (or $R_{1}=1 / t^{2}$ ).

In the case of equal surface temperatures, the ratio of heat fluxes given by Eq. (49) becomes

$$
\mathrm{Q}_{2} / \mathrm{Q}_{1}=\left(\frac{1}{\ln \mathrm{t}^{2}}-\frac{1}{\mathrm{t}^{2}-1}\right)^{-1}-1=-1-\left(\frac{1}{\ln \mathrm{R}_{1}}+\frac{\mathrm{R}_{1}}{1-\mathrm{R}_{1}}\right)^{-1}
$$

while the location of the maximum temperature given by Eq. (51) becomes:

$$
r_{m}{ }^{2} / r_{1}^{2}=\left(t^{2}-1\right) / \ell n t^{2} \quad \text { or } \quad R_{m}=-\frac{1-R_{1}}{\ell n R_{1}}
$$

or: $\quad r_{m}^{2}=\left(r_{2}^{2}-r_{1}^{2}\right) / \ln \left(r_{2}^{2} / r_{1}^{2}\right)$

Equation (52) for the difference between maximum and surface temperature may now be written:

$$
\delta T_{m}=\frac{t^{2}}{t^{2}-1}-\frac{1}{\ln t^{2}}+\frac{1}{\ln t^{2}} \ln \left(\frac{1-1 / t^{2}}{\ln t^{2}}\right)=\frac{1}{1-R_{1}}+\frac{1}{\ln R_{1}}\left[1-\ln \left(\frac{1-R_{1}}{-\ln R_{1}}\right)\right]
$$


Notice on Eq. (64) that $r_{m}$ varies from $r_{1}$ when $r_{1} / r_{2}=0$ (solid cylinder) to $\frac{r_{1}+r_{2}}{2}$, when $r_{1} / r_{2}=1$ (slab). By defining a new quantity

$$
\frac{r_{m}-r_{1}}{r_{2}-r_{1}}=\sqrt{\frac{\frac{r_{2}+r_{1}}{\left(r_{2}-r_{1}\right) \ln \left(r_{2} / r_{1}\right)}}{r_{2} / r_{1}-1}}
$$

we find that it increases from $0\left(r_{m}=r_{1}\right)$ to $1 / 2\left(r_{m}=\frac{r_{1}+r_{2}}{2}\right)$ when $r_{1} / r_{2}$ increases from 0 to 1 .

Figure (1) shows that $\frac{r_{m}-r_{1}}{r_{2}-r_{1}}$ is already greater than 0.4 , when $r_{1} / r_{2} \geq 0.10$;

the location of the maximum fuel temperature is nearly halfway through the fuel element when $r_{1} / r_{2} \geq 0.5$. Fig. 1 also shows that the ratio $Q_{1} / Q_{2}$ given by Eq. (62) increases from 0 to 1 when $r_{1} / r_{2}$ goes from 0 to 1 .

The various quantities mentioned above are given in Table I. It is found that the maximum compressive thermal stress is the same for external or internal cooling. The ratio of heat fluxes at the inside and outside boundaries (for cooling on both sides) is found to be equal to the ratio of maximum temperature differences for external and internal cooling respectively.

Table I allows comparison of various ways of cooling for uniform power density. For instance, for the same average power, the ratio of maximum fuel temperature drops, average fuel temperature drops and maximum compressive thermal stresses are readily derived from the table. Other comparisons of various types of cooling could be performed for the same maximum fuel temperature drop, or for the same maximum thermal stresses (either tensile, or compressive). For instance if the maximum. tensile thermal stress is to be kept the same for external cooling (e) or for cooling on both sides (b), the ratio of total heat generation 
in the fuel element reads:

$$
\frac{\mathrm{Q}_{\mathrm{b}}}{\mathrm{Q}_{\mathrm{e}}}=\frac{\left(\delta \mathrm{T}_{\mathrm{av}}\right)_{\mathrm{e}}}{\left(\delta \mathrm{T}_{\mathrm{av}{ }_{\mathrm{b}}}\right.}=\frac{1-\frac{2}{\mathrm{t}^{2}-1}\left(1-\frac{\ln \mathrm{t}^{2}}{\mathrm{t}^{2}-1}\right)}{\frac{\mathrm{t}^{2}+1}{t^{2}-1}-\frac{2}{\ell n t^{2}}}=\frac{1-\frac{2}{1 / \mathrm{R}_{1}-1}\left(1+\frac{\ell \mathrm{nR}}{1-\mathrm{R}_{1}-1}\right)}{\frac{1+\mathrm{R}_{1}}{1-\mathrm{R}_{1}}+\frac{2}{\ln \mathrm{R}_{1}}}
$$

The ratio of maximum fuel temperature drops becomes:

$$
\begin{aligned}
& \frac{\left(T_{m}-T_{s}\right)_{b}}{\left(T_{m}-T_{s}\right)_{e}}=\frac{Q_{b}}{Q_{e}} \frac{\left(\delta T_{m}\right)_{b}}{\left(\delta T_{m}\right)_{e}} \text {, or } \\
& \frac{\left(T_{m}-T_{s}\right)_{b}}{\left(T_{m}-T_{s}\right)_{e}}=\frac{\left(\delta T_{a v}\right)_{e}}{\left(\delta T_{a v}\right)_{b}} \frac{\left(\delta T_{m}\right)_{b}}{\left(\delta T_{m}\right)_{e}}=\frac{\left(\delta T_{m} / \delta T_{a v}\right)_{b}}{\left(\delta T_{m} / \delta T_{a v}\right)_{e}}
\end{aligned}
$$

with: $\frac{\left(\delta \mathrm{T}_{m}\right)_{b}}{\left(\delta \mathrm{T}_{m}\right)_{e}}=\frac{\frac{t^{2}}{t^{2}-1}-\frac{1}{\ln t^{2}}+\frac{1}{\ell n t^{2}} \ln \left(\frac{1-1 / t^{2}}{\ln t^{2}}\right)}{1-\frac{\ln t^{2}}{t^{2}-1}}$

Similarly, the ratio of maximum compressive stresses will be

$$
\frac{Q_{b}}{Q_{e}} \frac{\left(\delta T_{m}-\delta T_{a v}\right)_{b}}{\left(\delta T_{m}-\delta T_{a v}\right)_{e}}=\frac{\left(\delta T_{a v}\right)_{e}}{\left(\delta T_{a v}\right)_{b}} \frac{\left(\delta T_{m}-\delta T_{a v}\right)_{b}}{\left(\delta T_{m}-\delta T_{a v}\right)_{e}}
$$

or simply: $\frac{\left(\delta \mathrm{T}_{\mathrm{m}} / \delta \mathrm{T}_{\mathrm{av}}\right)_{\mathrm{b}}-1}{\left(\delta \mathrm{T}_{\mathrm{m}} / \delta \mathrm{T}_{\mathrm{av}}\right)^{-1}}$

with the values of $\delta T$ given in Table $I$. 
Let us recall that $R_{1}=0$ corresponds to a solid rod (no central hole), for which Table I gives the simple classical values:

$$
\delta T_{m}=\frac{4 \pi K}{Q}\left(T_{m}-T_{s}\right)=1
$$

or: $\quad T_{m}-T_{s}=\frac{Q}{4 \pi K}$

$$
\delta T_{a v}=\frac{4 \pi K}{Q}\left(T_{a v}-T_{s}\right)=\frac{1}{2}
$$

or: $\quad T_{a v}-T_{s}=\frac{Q}{8 \pi K}$

and finally $T_{m}-T_{a v}=\frac{Q}{8 \pi K}$

In the limiting case of a slab $t=1$, but since both $r_{2}$ and $r_{1}$ are infinite, (although their difference remains finite) the linear heat generation rate defined by Eq. (4) becomes infinite. In that case, one could define a dimensionless temperature:

$$
\frac{K T}{\left(r_{2}-r_{1}\right)^{2} H_{a v}}=\frac{r_{2}+r_{1}}{2\left(r_{2}-r_{1}\right)}\left(\frac{2 \pi K T}{Q}\right)=\frac{t+1}{2(t-1)}\left(\frac{2 \pi K T}{Q}\right)
$$

which remains finite when $t \rightarrow 1$. (Refer also to Appendix B).

(When $1 / t=0\left(\right.$ solid rod), the new dimensionless temperature is simply $\left.\frac{\pi K T}{Q}.\right)$

I'hese dimensionless quantities will be plotted for the three special cases considered in Table $I$. Since $\frac{K T}{\left(r_{2}-r_{1}\right)^{2} H_{a v}}$ is proportional to $\left(\frac{4 \pi K}{Q} T\right)$ 
(for the a given value of $t$ ), the ratios of these quantities is obviously the same as the ratio of $\delta T^{\prime} s$.

For instance, Figure (2) shows the variations of $\frac{\mathrm{K}\left(\mathrm{T}_{\mathrm{m}}-\mathrm{T}_{\mathrm{s}}\right)}{\left(\mathrm{r}_{2}-\mathrm{r}_{1}\right)^{2} \mathrm{H}_{\mathrm{av}}}$, $\frac{K\left(T_{a v}-T_{s}\right)}{\left(r_{2}-r_{1}\right)^{2} H_{a v}}$ and $\frac{K\left(T_{m}-T_{a v}\right)}{\left(r_{2}-r_{1}\right)^{2} H_{a v}}$ versus $r_{1} / r_{2}$ for external cooling. These values are found to increase respectively from $1 / 4$ to $1 / 2,1 / 8$ to $1 / 3$ and $1 / 8$ to $1 / 6$ when $r_{1} / r_{2}$ increases from 0 (solid rod) to 1 (slab).

The same quantities are plotted on Fig. 3 for internal cooling. While the dimensionless values of $\left(\mathrm{T}_{\mathrm{m}}-\mathrm{T}_{\mathrm{s}}\right)$ and $\left(\mathrm{T}_{\mathrm{av}}-\mathrm{T}_{\mathrm{s}}\right)$ decrease to $1 / 2$ and $1 / 3$ respectively, $\frac{K\left(T_{m}-T_{a v}\right)}{\left(r_{2}-r_{1}\right)^{2} H_{a v}}$ increases from $1 / 8$ to $1 / 6$ since it is the same as in Fig. 2. Finally, Figure 4 shows the variations of the same quantities when both boundaries are cooled at the same temperature; they decrease respectively from $1 / 4$ to $1 / 8,1 / 8$ to $1 / 12$, and $1 / 8$ to $1 / 24$ when $\mathrm{r}_{1} / \mathrm{r}_{2}$ increases from 0 to 1 . Figures $5-7$ show the variations of $\frac{4 \pi K}{Q}\left(T_{m}-T_{s}\right), \frac{4 \pi K}{Q}\left(T_{a v}-T_{s}\right)$ and $\frac{4 \pi K}{Q}\left(T_{m}-T_{a v}\right)$ for the 3 types of cooling.

Table II gives numerical values for various quantities of interest in the special case where $r_{2} / r_{1}=2$. For the same power density, temperature drops and stresses are lower by factors between 3 and 6 for cooling on both sides compared to one side cooling; external cooling yields maximum and average temperature drops $63 \%$ and $51 \%$ of their values for internal cooling. With the same maximum temperature drop in the fuel, the stresses are not much different with cooling on both sides while the heat flux is multiplied by 3 to 5 ; compared to one side cooling; there is a 57\% increase in flux for external cooling compared to internal cooling. Finally, for the same maximum tensile thermal stress (or the same average fuel temperature drop), cooling on both sides leads to 
increase by factors 3 to 6 in heat flux for comparable values of the maximum temperature drop; external cooling nearly doubles the heat flux obtained with internal cooling for a $25 \%$ increase in the maximum temperature drop.

Figs. 8, 9 and 10 compare the three ways of cooling for the same power density. Maximum fuel temperature drop and thermal stresses are always smaller for 2 sides cooling compared to external cooling, the ratios decreasing from 1 to $1 / 4$ when $r_{1} / r_{2}$ increases from 0 to 1 (Fig. 8 ). Maximum temperature drop and stresses are still always smaller with cooling on both sides than with internal cooling (Fig. 9) but now maximum and average temperature drop ratios increase from 0 to $1 / 4$ when $r_{1} / r_{2}$ increases from 0 to 1 . Fig. 10 shows that both maximum and average temperature drops are smaller with external than with internal cooling and that the ratios increase from 0 to 1 when $r_{1} / r_{2}$ goes from 0 to 1 .

Figs. 11 - 13 correspond to the same maximum fuel temperature drop. Comparing 2 sides cooling with external cooling (Fig. 11) the power density is increased by factors increasing from 1 to 4 when $r_{1} / r_{2}$ increases from 0 (solid rod) to 1 (slab), while the thermal stresses vary by $25-33 \%$ at most; the tensile stress is slightly higher and the compressive stress lower with 2 sides cooling. As seen on Fig. 12, the power density with inner cooling increases from 0 to $25 \%$ of the value with cooling on both sides when $r_{1} / r_{2}$ increases from 0 to 1 ; the maximum tensile stress is always larger with internal cooling, while the compressive stress is smaller. Fig. 13 shows that both power density (and compressive stress) are always smaller with internal cooling compared to external cooling, but the tensile stress is always larger.

In the case of same average temperature drop (or maximum tensile thermal stress), Fig. 14 shows that the ratio of heat fluxes with both sides cooled increases from 0 to 4 when $r_{1} / r_{2}$ goes from 0 to 1 when compared to external cooling. Both maximum temperature drops and maximum 
compressive thermal stresses are lower when both sides are cooled. With internal cooling, as compared to cooling on both sides, the heat flux ratio increases from 0 to $1 / 4$ when $r_{1} / r_{2}$ increases from 0 to 1 (Fig. 15). The ratio of maximum temperature drops and compressive stresses increase from 0 to 1 , but the maximum temperature drop ratio is already close to $75 \%$ when the ratio of heat fluxes is only about $10 \%$ (for $r_{1} / r_{2} \cong 0.15$ ). Finally, the comparison between internal and external cooling is shown on Fig. 16: the ratio of heat fluxes (equal to the ratio of compressive stresses) increases from 0 to 1 when $r_{1} / r_{2}$ increases from 0 to 1 , while the ratio of maximum temperature drops increases from $1 / 2$ to 1 .

\section{CONCLUSIONS}

Cooling a hollow fuel element on both sides rather than on only one side allows significant reduction in maximum fuel temperature drop and maximum thermal stresses (tensile and compressive) for a given power density. Conversely, the power density may be significantly increased when either maximum temperature drop or thermal stresses are kept the same. For instance, for the same maximum fuel temperature, the power density could be increased by a factor of 3-4 by going from one side to two sides cooling, without increasing the maximum thermal stresses (for a ratio of rod O.D. to I.D. of 2 ).

As expected, external cooling leads to lower temperatures and stresses than internal cooling for the same power density. In the preceding example, the average fuel temperature drop is reduced by a factor of 2, and the maximum temperature drop is reduced by 1.5 ; the maximum compressive thermal stresses are equal.

While these results are obtained for uniform power density (Appendix A) general relations have been derived for radial variations of the power density across the fuel rod and arbitrary values of the heat transfer coefficient on either side of the fuel element. Our results 
are applicable to the case of temperature dependent fuel conductivity by replacing temperature differences $\left(\mathrm{T}_{j}-\mathrm{T}_{i}\right)$ by the thermal conductivity integral $\frac{1}{K_{a v}} \int_{T_{i}}^{T j} K d T$.

Dimensionless temperature differences of interest, such as the maximum temperature drop in the fuel, only depend upon the power distribution, the ratio of radii and on the dimensionless difference between surface temperatures.

The case of slab geometry which is a special case of the hollow fuel element is treated specifically in Appendix B.

Finally, we have derived in Appendix $C$ the distribution of thermal stresses, radial, tangential, and axial. We have shown that, in general, the dimensionless stresses only depend upon the geometry $\left(R_{1}=r_{1}{ }^{2} / r_{2}{ }^{2}\right.$, $\left.R=r^{2} / r_{2}{ }^{2}\right)$, the distribution of power density $\left(\mathrm{H} / \mathrm{H}_{\mathrm{av}}\right)$ and the difference between dimensionless surface temperatures, $\theta_{1}-\theta_{2}=\frac{4 \pi K}{Q}\left(T_{1}-T_{2}\right)$. In the case of uniform power density, the last parameter $\left(\theta_{1}-\theta_{2}\right)$ may be replaced by the dimensionless location of the maximum fuel temperature $R_{m}=r_{m}{ }^{2} / r_{2}{ }^{2}$.

Fig. 20 shows typical distribution of stresses for uniform power density and equal surface temperatures while the ratio of maximum tangential and axial compressive stresses is plotted on Fig. 21. The variation of the maximum compressive stress is shown on Fig. 22 versus the location of the maximum fuel temperature: while the stresses are equal and largestfor one-side cooling (internal or external), the smallest value of the stress is not reached when the surface temperatures are equal, but is very close to it (except for the case of the slab when these two locations coincide as shown on Fig. 23). 


\section{LIST OF SYMBOLS}

$$
\begin{aligned}
& \begin{array}{l}
\mathrm{b}=\frac{\mathrm{hl}}{\mathrm{K}} \\
\mathrm{B}=\frac{\mathrm{rh}}{\mathrm{K}}
\end{array} \mid=\text { Biot number } \\
& \mathrm{E}=\text { Young's modulus } \\
& \mathrm{h}=\text { surface heat transfer coefficient } \\
& \mathrm{H}=\text { power density } \\
& J \quad=-\int_{r_{1}}^{r_{2}} r \ln \left(r / r_{2}\right) H(r) d r / \int_{r_{1}}^{r} r H(r) d r \\
& \mathrm{~K}=\text { fuel thermal conductivity } \\
& \ell=r_{2}-r_{1} \\
& \text { L } \quad=\frac{1}{2} \int_{r_{1}}^{r_{2}} r^{3} H(r) d r\left\{\left(r_{2}{ }^{2}-r_{1}{ }^{2}\right) \int_{r_{1}}^{r_{2}} r H(r) d r\right\}^{-1} \text {. } \\
& \mathrm{P} \quad=\mathrm{H} / \mathrm{H}_{\mathrm{av}} \\
& \text { Q }=\text { heat flux per unit length } \\
& \mathbf{r}=\text { radius } \\
& \mathrm{R}=\mathrm{r}^{2} / \mathrm{r}_{2}{ }^{2} \\
& \mathrm{R}_{1}=\mathrm{r}_{1}{ }^{2} / \mathrm{r}_{2}{ }^{2} \\
& S \quad=\frac{4 \pi K}{Q} B T_{S} \\
& t=r_{2} / r_{1} \\
& \mathrm{~T}=\text { fuel temperature referred to the bulk coolant temperature } \\
& y \quad=\frac{r-r_{1}}{r_{2}-r_{1}}
\end{aligned}
$$




$$
\begin{aligned}
\alpha & =1 \text { inear expansion coefficient } \\
\theta & =4 \pi K T / Q \text { dimensionless temperature } \\
\nu & =\text { Poisson's ratio } \\
\sigma & =\text { thermal stress } \\
\Sigma & =\frac{4 \pi K(1-\nu) \sigma}{\alpha E Q} \text { dimensionless stress }
\end{aligned}
$$

\section{Subscripts}

$\begin{array}{ll}1 & =\text { inner surface } \\ 2 & =\text { outer surface } \\ \text { av } & =\text { average } \\ \text { b } & =2 \text { sides cooling } \\ \text { e } & =\text { external } \\ i & =\text { internal } \\ \mathrm{m} & =\text { maximum } \\ \mathrm{s} & =\text { surface }\end{array}$


TABLE I: DIMENSIONLESS TEMPERATURES AND STRESSES FOR VARIOUS TYPES OF COOLING

(UNIFORM POWER DENSITY)

\begin{tabular}{|c|c|c|c|}
\hline & EXTERNAL COOLING & INTERNAL COOLING & EQUAL SURFACE TEMPERATURES \\
\hline $\begin{array}{l}\text { Surface Temperature* } \\
S=\frac{4 \pi K}{Q} B T_{S}\end{array}$ & 2 & 2 & $\begin{array}{l}\left.\text { (With } B=B_{1}\right) \\
-2\left(\frac{1}{\operatorname{lnR} R_{1}}+\frac{R_{1}}{1-R_{1}}\right)\end{array}$ \\
\hline $\begin{array}{l}\text { Maximum Fue } 1 \\
\text { Temperature Drop } \\
\delta \mathrm{T}_{\mathrm{m}}=\frac{4 \pi \mathrm{K}}{\mathrm{Q}}\left(\mathrm{T}_{\mathrm{m}}-\mathrm{T}_{\mathrm{s}}\right)\end{array}$ & $1+\frac{R_{1} \ell n R_{1}}{1-R_{1}}$ & $-\left(1+\frac{\ln R_{1}}{1-R_{1}}\right)$ & $\frac{1}{1-R_{1}}+\frac{1}{\ln R_{1}}\left[1-\ln \left(\frac{1-R_{1}}{-\ln R_{1}}\right.\right.$ \\
\hline $\begin{array}{l}\text { Average Fuel } \\
\text { Temperature Drop } \\
\delta \mathrm{T}_{\mathrm{av}}=\frac{4 \pi \mathrm{K}}{\mathrm{Q}}\left(\mathrm{T}_{\mathrm{av}}-\mathrm{T}_{\mathrm{s}}\right) \\
\text { (Max.Tensile } \\
\text { thermal stress) }\end{array}$ & $\frac{1}{2}-\frac{R_{1}}{1-R_{1}}\left(1+\frac{R_{1} \ell n R_{1}}{1-R_{1}}\right.$ & $-\frac{1}{2}-\frac{1}{1-R_{1}}\left(1+\frac{\ln R_{1}}{1-R_{1}}\right)$ & $\frac{1}{2} \frac{1+R_{1}}{1-R_{1}}+\frac{1}{\ln R_{1}}$ \\
\hline $\begin{array}{l}\delta \mathrm{T}_{\mathrm{m}}-\delta \mathrm{T}_{\mathrm{av}} \\
\text { (Max. compressive } \\
\text { thermal stress) }\end{array}$ & $\frac{1}{2} \frac{1+R_{1}}{1-R_{1}}+\frac{R_{1} \ln R_{1}}{\left(1-R_{1}\right)^{2}}$ & $\frac{1}{2} \frac{1+R_{1}}{1-R_{1}}+\frac{R_{1} \ell R_{1}}{\left(1-R_{1}\right)^{2}}$ & $\frac{1}{2}-\frac{1}{\ln R_{1}} \ln \left(\frac{1-R_{1}}{-\ln R_{1}}\right)$ \\
\hline
\end{tabular}

* Reference to bulk coolant temperature (same on both sides)

**Ratio of Biot numbers: $\frac{B_{1}}{B_{2}}=-\frac{1+R_{1} \ell n R_{1} /\left(1-R_{1}\right)}{1+\ell n R_{1} /\left(1-R_{1}\right)}=\frac{Q_{1}}{Q_{2}}$ : ratio of heat fluxes. $\quad R_{1}=r_{1}{ }^{2} / r_{2}{ }^{2}$ 
TABLE II: COMPARISON OF VARIOUS TYPES OF COOLING UNIFORM POWER DENSITY $\left(r_{2} / r_{1}=2\right)$

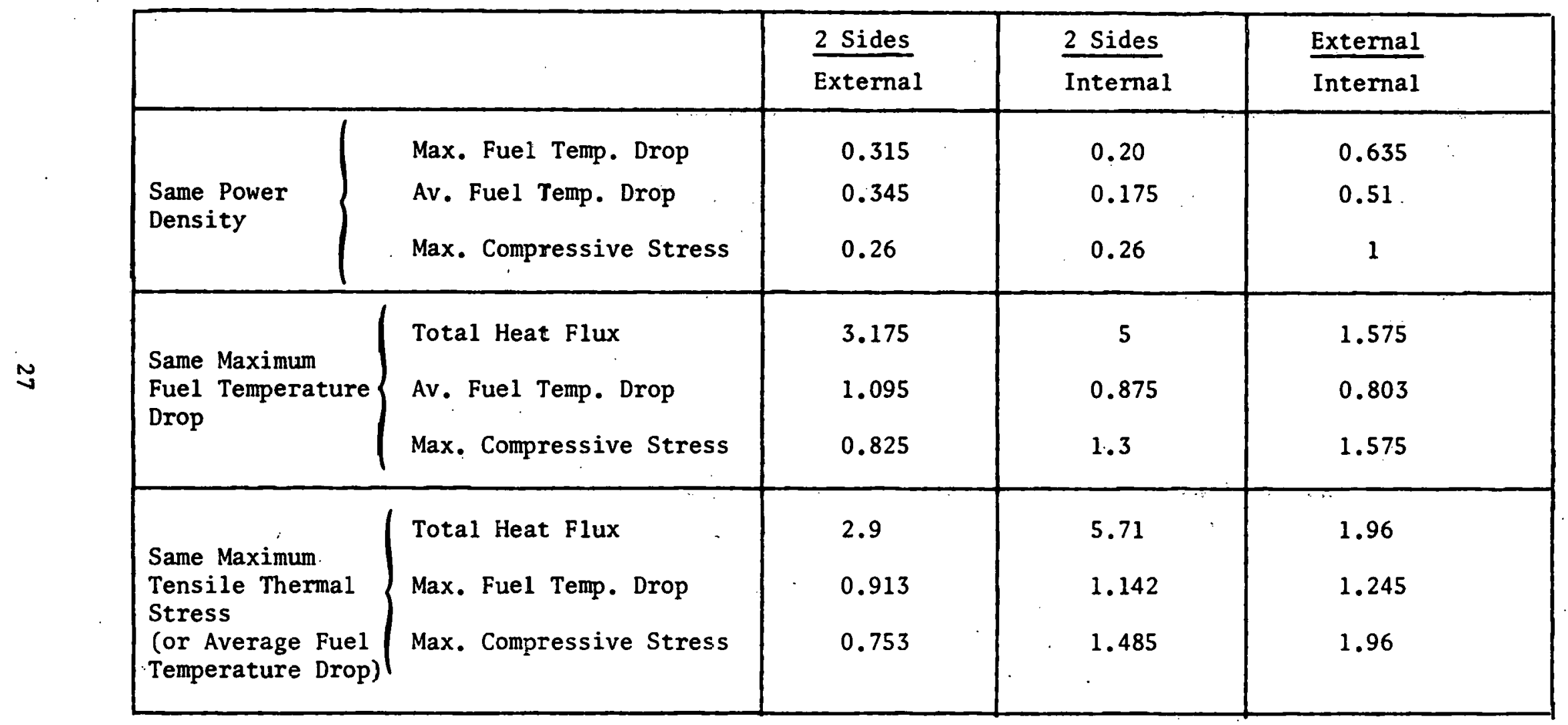


APPENDIX A

Maximum and Average Fuel Temperatures for Uneven Cooling on Both Sides and Uniform Power Density

The difference between the two surface' temperatures may be written (see Eq. 25)

$$
\frac{2 \pi K}{Q}\left\{T\left(r_{1}\right)-T\left(r_{2}\right)\right\}=\frac{\left(1+B_{2} / B_{1}\right) J / \ln \left(r_{2} / r_{1}\right)-1}{\left(1+B_{2} / B_{1}\right) / \ln \left(r_{2} / r_{1}\right)+B_{2}}
$$

The location of the maximum fuel temperature may now be written (see Eq. 27 and $25^{\circ}$ )

$\frac{\mathrm{Q}_{1}}{\mathrm{Q}_{2}}=\frac{2 \pi}{\mathrm{Q}} \int_{\mathrm{r}_{1}}^{\mathrm{r}} \mathrm{r}^{\circ} \mathrm{Hdr} \mathrm{r}^{-}=\frac{-1}{\ln \left(\mathrm{R}_{1}\right)}\left\{2 \mathrm{~J}-\frac{4 \pi \mathrm{K}}{\mathrm{Q}}\left[\mathrm{T}\left(\mathrm{r}_{1}\right)-\mathrm{T}\left(\mathrm{r}_{2}\right)\right]\right\}=\frac{1}{1-\mathrm{R}_{1}} \int_{\mathrm{R}_{1}}^{\mathrm{R}} \frac{\mathrm{H}}{\mathrm{H}_{\mathrm{av}}} \mathrm{dR}^{-}$

For a given geometry, $R_{1}=\left(r_{1} / r_{2}\right)^{2}$, and distribution of power density $\left(\mathrm{H} / \mathrm{H}_{\mathrm{av}}\right)$, the ratio of fluxes, relative location of maximum temperature and maximum temperature drop only depend upon the dimensionless difference between surface temperatures.

We have plotted $y_{m}=\frac{r_{m}-r_{1}}{r_{2}-r_{1}}$ versus $\frac{r_{1}}{r_{2}}$ and $\frac{r_{2}+r_{1}}{r_{2}-r_{1}} \cdot \frac{\pi K}{Q}\left\{T\left(r_{1}\right)-T\left(r_{2}\right)\right\}$ 
on Fig. 17 and also $\left(1-\frac{r_{1}^{2}}{r_{2}{ }^{2}}\right) \frac{\pi K}{Q}\left\{T_{m}-T\left(r_{2}\right)\right\}$ versus $r_{m} / r_{2}$ (Fig. 18) since we now find for uniform power density

$R_{m}=\frac{r_{m}^{2}}{r_{2}{ }^{2}}=\frac{1-r_{1}{ }^{2} / r_{2}^{2}}{\ln \left(r_{2}{ }^{2} / r_{1}{ }^{2}\right)}\left[1-\frac{4 \pi K}{Q}\left\{T\left(r_{1}\right)-T\left(r_{2}\right)\right\}\right]=-\frac{1-R_{1}}{\ln R_{1}}\left[1-\left(\theta_{1}-\theta_{2}\right)\right]$

and $\frac{4 \pi K}{Q}\left\{T_{m}-T\left(r_{2}\right)\right\}\left(1-\frac{r_{1}^{2}}{r_{2}{ }^{2}}\right)=1-\frac{r_{m}{ }^{2}}{r_{2}{ }^{2}}\left[1+\ln \left(\frac{r_{2}^{2}}{r_{m}{ }^{2}}\right)\right]$

or $\quad\left(1-R_{1}\right)\left(\theta_{m}-\theta_{2}\right)=1-R_{m}\left(1-\ell n R_{m}\right)$

Fig. (19) shows the variations of $\frac{1-r_{1}{ }^{2} / r_{2}{ }^{2}}{\ln \left(r_{2}{ }^{2} / r_{1}{ }^{2}\right)}$ versus $r_{1} / r_{2}$, which corresponds to Eq. (A-2) for $r_{m}{ }^{2} / r_{2}{ }^{2}$. The maximum values of $\left(T_{1}-T_{2}\right)$ and $\left(T_{2}-T_{1}\right)$ are also plotted (which correspond to $\mathrm{T}_{\mathrm{m}}-\mathrm{T}_{\mathrm{s}}$ on Fig. 5 for external cooling and internal cooling respectively).

Let us recall that the ratio of fluxes could be written

$$
\frac{Q_{1}}{Q_{2}}=\frac{r_{m}^{2}-r_{1}^{2}}{r_{2}^{2}-r_{m}^{2}}=\frac{r_{m}^{2} / r_{2}^{2}-r_{1}^{2} / r_{2}^{2}}{1-r_{m}^{2} / r_{2}^{2}}=\frac{R_{m}-R_{1}}{1-R_{m}}
$$

where $\frac{r_{m}^{2}}{r_{2}^{2}}$ is given by Eq. (A-2). Therefore, $Q_{1} / Q_{2}$ only depends upon $r_{1} / r_{2}$ and $\frac{4 \pi K}{Q}\left[T\left(r_{1}\right)-T\left(r_{2}\right)\right]$, as does $\frac{4 \pi K}{Q}\left[T_{m}-T\left(r_{2}\right)\right]$ derived from Eq. $(A-3)$ and $(A-2)$.

The dimensionless average temperature difference may also be written as 
a function of these two parameters as shown in Eq. (30)

$$
\begin{aligned}
& \frac{2 \pi K}{Q}\left\{T_{a v}-T\left(r_{2}\right)\right\}=-L+\frac{1 / 2}{1-r_{1}{ }^{2} / r_{2}{ }^{2}}-\frac{J}{\ell n\left(r_{2}{ }^{2} / r_{1}{ }^{2}\right)}+\frac{2 \pi K}{Q}\left\{T\left(r_{1}\right)-T\left(r_{2}\right)\right\} \\
& x\left\{\frac{1}{\ln \left(r_{2}^{2} / r_{1}^{2}\right)}-\frac{1}{r_{2}^{2} / r_{1}^{2}-1}\right\} \\
& \text { or: } \quad \theta_{\text {av }}-\theta_{2}=-2 \mathrm{~L}+\frac{1}{1-\mathrm{R}_{1}}+\frac{2 \mathrm{~J}}{\ell \mathrm{n} \mathrm{R}_{1}}-\left(\Theta_{1}-\Theta_{2}\right)\left(\frac{1}{\ln \mathrm{R}_{1}}+\frac{\mathrm{R}_{1}}{1-\mathrm{R}_{1}}\right)
\end{aligned}
$$

The average temperature difference only depends upon the dimensionless difference in surface temperatures for a given geometry $\left(R_{1}\right)$ and power distribution $\left(\mathrm{H} / \mathrm{H}_{\mathrm{av}}\right)$ in the integrals $\mathrm{L}$ and $\mathrm{J}$.

For uniform power density this relation becomes =

$$
\theta_{\mathrm{av}}-\theta_{2}=\frac{1}{2} \frac{1+\mathrm{R}_{1}}{1-\mathrm{R}_{1}}+\frac{1}{\ln \mathrm{R}_{1}}-\left(\theta_{1}-\theta_{2}\right)\left(\frac{1}{\operatorname{lnR} \mathrm{R}_{1}}+\frac{\mathrm{R}_{1}}{1-\mathrm{R}_{1}}\right)
$$

Notice that for uniform power density, Eq. (25 ) reads:

$$
\Theta_{1}-\Theta_{2}=\frac{\frac{1}{\ln R_{1}}+\frac{\mathrm{R}_{1}}{1-\mathrm{R}_{1}}+\frac{1}{1+\mathrm{B}_{2} / \mathrm{B}_{1}}}{\frac{1}{\ln \mathrm{R}_{1}}-\frac{\mathrm{B}_{2} / 2}{1+\mathrm{B}_{2} / \mathrm{B}_{1}}}
$$

and could be substituted into Eq. $(A-6)$.

We found already that the two surface temperatures are equal when the ratio of Biot numbers reads

$$
\frac{\mathrm{B}_{2}}{\mathrm{~B}_{1}}=\frac{\ln \left(\mathrm{r}_{2} / \mathrm{r}_{1}\right)}{\mathrm{J}}-1=-\left(\frac{1}{\ln \mathrm{R}_{1}}+\frac{\mathrm{R}_{1}}{1-\mathrm{R}_{1}}\right)^{-1}-1
$$


$T\left(r_{1}\right)>T\left(r_{2}\right)$ when $B_{2} / B_{1}$ is greater than this critical ratio, and vice versa. Notice that the function $Q_{1} / Q_{2}$ shown on $F i g .1$ also represents the critical value of $B_{1} / B_{2}$.

We find from $\mathrm{Eq}$. (A-1) that a true maximum value of the temperature occurs within the fuel provided

$$
r_{1}^{2} \leq r_{m}^{2} \leq r_{2}^{2} \text { or } \quad R_{1} \leq R_{m} \leq 1
$$

i.e. for the following conditions for the dimensionless difference between surface temperatures, which are always satisfied:

$$
1+\frac{\ell n R_{1}}{1-R_{1}} \leq \frac{4 \pi K}{Q}\left\{T\left(r_{1}\right)-T\left(r_{2}\right)\right\}=\theta_{1}-\theta_{2} \leq 1+\frac{R_{1} \ell n R_{1}}{1-R_{1}}
$$

The largest value of $T\left(r_{2}\right)-T\left(r_{1}\right)$ is obtained for $B_{2}=0$ when the maximum temperature occurs at the outer surface; similarly, the largest value of $T\left(r_{1}\right)-T\left(r_{2}\right)$ corresponds to the maximum temperature at the inner surface $\left(B_{1}=0\right)$. 
APPENDIX B

Remarks about the Special Case of a Slab

In that case, the Biot numbers should be based on the slab thickness $\left(r_{2}-r_{1}\right)$

$$
b_{1}=h_{1} \frac{r_{2}-r_{1}}{K}, b_{2}=h_{2} \frac{r_{2}-r_{1}}{K}
$$

and are related to the Biot numbers $B_{i}=\frac{h_{i} r_{i}}{K}$ :

$$
\begin{aligned}
& b_{1}=(t-1) B_{1} \\
& b_{2}=\frac{t-1}{t} B_{2}
\end{aligned} \quad\left(t=r_{2} / r_{1}\right)
$$

The dimensionless temperature is defined as:

$$
\frac{K T}{\left(r_{2}-r_{1}\right)^{2} H_{a v}}=\frac{t+1}{2(t-1)} \quad\left(\frac{2 \pi K T}{Q}\right)
$$

The formulae derived previously are still applicable provided one replaces $\ln \left(r / r_{2}\right)$ by $r / r_{2}-1$ and $\ln \left(r_{2} / r_{1}\right)$ by $\left(r_{2} / r_{1}-1\right)$ since $r_{1}, r_{2}+\infty$. For instance, the integral $\mathrm{J}$ given by Eq. (22) becomes

$$
J=\frac{r_{2}-r_{1}}{H_{a v} \frac{r_{2}+r_{1}}{2}} \int_{0}^{1}(1-y) H d y
$$


with $y=\frac{r-r_{1}}{r_{2}-r_{1}}$ and $H_{a v}=\int_{0}^{1} H d y$

Therefore: $\frac{\mathrm{J}}{\ln \left(\mathrm{r}_{2} / \mathrm{r}_{1}\right)} \rightarrow \int_{0}^{1}(1-y) \frac{\mathrm{Hdy}}{\mathrm{H}_{\mathrm{av}}}=1-\frac{\int_{0}^{1} y \text { Hdy }}{\int_{0}^{1} H d y}$.

Equations (23) to (30) may now be written, if we call the thickness of the slab $\mathrm{r}_{2}-\mathrm{r}_{1}=\ell$

$$
\begin{aligned}
& \frac{K T_{1}}{\ell^{2} H_{a v}}=\frac{\frac{1}{b_{2}}+1-\int_{0}^{1} y \frac{H}{H_{a v}} d y}{1+\frac{b_{1}}{b_{2}}+b_{1}} \\
& \frac{K T_{2}}{\ell^{2} H_{a v}}=\frac{\frac{1}{b_{1}}+\int_{0}^{1} y \frac{H}{H_{a v}} d y}{1+b_{2} / b_{1}+b_{2}} \\
& \frac{K\left(T_{1}-T_{2}\right)}{\ell^{2} H_{a v}}=\frac{\frac{1}{1+b_{1} / b_{2}}-\int_{0}^{1} y \frac{H}{H_{a v}} d y}{\frac{1}{1 / b_{1}+1 / b_{2}}+1} \\
& \frac{Q_{1}}{Q_{2}}=\frac{\frac{1}{b_{2}}+1-\int_{0}^{1} y \frac{H}{H_{a v}} d y}{\frac{1}{b_{1}}+\int_{0}^{1} y \frac{H}{H_{a v}} d y} \\
& \int_{0}^{\mathrm{y}} \frac{\mathrm{H}}{\mathrm{H}_{\mathrm{av}}} \mathrm{dy}=\frac{\frac{1}{\mathrm{~b}_{2}}+1-\int_{0}^{1} y \frac{\mathrm{H}}{\mathrm{H}_{\mathrm{av}}} \mathrm{dy}}{\frac{1}{\mathrm{~b}_{2}}+\frac{1}{\mathrm{~b}_{1}}+1}=1-\int_{0}^{1} y \frac{H}{\mathrm{H}_{\mathrm{av}}} d y-\frac{K\left(\mathrm{~T}_{1}-\mathrm{T}_{2}\right)}{\ell^{2} \mathrm{H}_{\mathrm{av}}}
\end{aligned}
$$




$$
\frac{K\left(t_{m}-T_{2}\right)}{e^{2} H_{a v}}=\int_{y_{m}}^{l}(1-y) \frac{H}{H_{a v}} d y=\int_{0}^{1-y_{m}} \times \frac{H}{H_{a v}} d x
$$

Therefore $\frac{K\left(\mathrm{~T}_{\mathrm{m}}-\mathrm{T}_{2}\right)}{\ell^{2} \mathrm{H}_{\mathrm{av}}}$ only depends upon $\frac{\mathrm{K}\left(\mathrm{T}_{1}-\mathrm{T}_{2}\right)}{\ell^{2} \mathrm{H}_{\mathrm{av}}}$ for a given power distribution. (Refer to Eq. B-8 for $y_{m}$ ).

$$
\frac{K\left(T_{a v}-T_{2}\right)}{\ell^{2} H_{a v}}=\frac{1}{2}\left\{\frac{\frac{1}{b_{1}}+\int_{0}^{1} y \frac{H}{H_{a v}} d y}{\frac{1}{b_{2}}+\frac{1}{b_{1}}+1}-\int_{0}^{1} y^{2} \frac{H}{H_{a v}} d y\right\}
$$

or simply,

$$
\frac{K}{\ell^{2} H_{a v}}\left(T_{a v}-\frac{T_{1}+T_{2}}{2}\right)=\frac{1}{2} \int_{0}^{1} y(1-y) \frac{H}{H_{a v}} d y
$$

Both $\frac{K\left(T_{a v}-T_{2}\right)}{\ell^{2} H_{a v}}$ and $\frac{K\left(T_{m}-T_{a v}\right)}{\ell^{2} H_{a v}}$ only depend upon $\frac{K\left(T_{1}-T_{2}\right)}{\ell^{2} H_{a v}}$ for a given

power distribution.

Finally, for uniform power density, the following simple results are found:

$$
\begin{aligned}
& \frac{K T_{1}}{\ell^{2} H_{a v}}=\frac{1}{b_{1}} \frac{\frac{1}{b_{2}}+\frac{1}{2}}{1+\frac{1}{b_{1}}+\frac{1}{b_{2}}} \\
& \frac{K T_{2}}{\ell^{2} H_{a v}}=\frac{1}{b_{2}} \frac{\frac{1}{b_{1}}+\frac{1}{2}}{1+\frac{1}{b_{1}}+\frac{1}{b_{2}}}
\end{aligned}
$$




$$
\begin{aligned}
& \frac{K\left(T_{1}-T_{2}\right)}{\ell^{2} H_{a v}}=\frac{1}{2} \frac{\frac{1}{b_{1}}-\frac{1}{b_{2}}}{1+\frac{1}{b_{1}}+\frac{1}{b_{2}}} \\
& \frac{Q_{1}}{Q_{2}}=\frac{\frac{1}{b_{2}}+1 / 2}{\frac{1}{b_{1}}+1 / 2} \\
& y_{m}=\frac{1}{2}-\frac{K\left(T_{1}-T_{2}\right)}{\ell^{2} H_{a v}}=\frac{\frac{1}{b_{2}}+\frac{1}{2}}{\frac{1}{b_{1}}+\frac{1}{b_{2}}+1} . \\
& \frac{K\left(T_{m}-T_{2}\right)}{\ell^{2} H_{a v}}=\frac{1}{2}\left(1-y_{m}\right)^{2}=\frac{1}{8}\left[1+\frac{2 K\left(T_{1}-T_{2}\right)}{\ell^{2} H_{a v}}\right]^{2}=\frac{1}{8}\left(\frac{\frac{2}{\mathrm{~b}_{1}}+1}{\frac{1}{b_{1}}+\frac{1}{b_{2}}+1}\right)^{2} \\
& \frac{K\left(T_{a v}-T_{2}\right)}{\ell^{2} H_{a v}}=\frac{1}{4} \frac{\frac{2}{b_{1}}+1}{\frac{1}{b_{1}}+\frac{1}{b_{2}}+1}-\frac{1}{6}=\frac{1}{12}+\frac{K\left(T_{1}-T_{2}\right)}{2 \ell^{2} H_{a v}}
\end{aligned}
$$

which could be written: $\frac{K}{\ell^{2} H_{a v}}\left(T_{a v}-\frac{\left.T_{1}+T_{2}\right)}{2}\right)=\frac{1}{12}$

The difference between maximum and average fuel temperatures now reads:

$$
\frac{K\left(T_{m}-T_{a v}\right)}{\ell^{2} H_{a v}}=\frac{1}{24}+\frac{1}{2}\left(\frac{K\left(T_{1}-T_{2}\right)}{\ell^{2} H_{a v}}\right)^{2}=\frac{1+3\left(1-2 y_{m}\right)^{2}}{24}
$$


and therefore the minimum compressive thermal stresses is obtained when the surface temperatures are equal. $\left(y_{m}=1 / 2\right)$

The special cases of internal cooling $\left(b_{2}=0\right)$, external cooling $\left(b_{1}=0\right)$ and equal surface temperatures $\left(b_{1}=b_{2}\right)$ are readily derived and correspond to the value $r_{1} / r_{2}=1$ in the tables and figures obtained previously.

For instance, when $b_{1}=b_{2}$ and $T_{1}=T_{2}=T_{s}$, one finds $y_{m}=\frac{1}{2}$, $\frac{K\left(T_{m}-T_{s}\right)}{\ell^{2} H_{a v}}=\frac{1}{8}, \frac{K\left(T_{a v}-T_{s}\right)}{\ell^{2} H_{a v}}=\frac{1}{12}$ and $\frac{K\left(T_{m}-T_{a v}\right)}{\ell^{2} H_{a v}}=\frac{1}{24}$.

When $b_{1}=0, T_{1}=T_{m}, T_{2}=T_{s}, y_{m}=0$ and $\frac{K\left(T_{m}-T_{s}\right)}{\ell^{2} H_{a v}}=\frac{1}{2}$, $\frac{K\left(T_{a v}-T_{s}\right)}{\ell^{2} H_{a v}}=\frac{1}{3}$ and $\frac{K\left(T_{m}-T_{a v}\right)}{\ell^{2} H_{a v}}=\frac{1}{6}$

36 
APPENDIX C

Derivation of Elastic Thermal Stress Distributions

For a thick walled long hollow cylinder with the boundary conditions, $\sigma_{r}=0$ at both surfaces, the thermal stresses could be written as functions of the temperature distribution *

$$
\begin{array}{ll}
\begin{array}{ll}
\text { radial } \\
\text { stress }
\end{array} & \sigma_{r}=\frac{\alpha E}{1-\nu}\left[\frac{1}{2}\left(1-r_{1}{ }^{2} / r_{2}\right) T_{a v}-\frac{1}{2} \int_{r_{1}}^{r} r \mathrm{~T} r\right] \\
\begin{array}{ll}
\text { tangential } \\
\text { stress }
\end{array} & \sigma_{\theta}=\frac{\alpha E}{1-\nu}\left[\frac{1}{2}\left(1+r_{1}{ }^{2} / r^{2}\right) \cdot T_{a v}+\frac{1}{r^{2}} \int_{r_{1}}^{r} r \mathrm{Tdr}-\mathrm{T}\right]
\end{array}
$$

Axial Stress

$$
\sigma_{z}=\sigma_{r}+\sigma_{\theta}=\frac{\alpha E}{1-\nu} \quad\left(T_{a v}-\mathrm{T}\right)
$$

$a, E$, and $v$ are the linear expansion coefficient, Young's modulus and Poisson ratio respectively. We shall define a dimensionless stress and use the dimensionless temperature: $\theta=\frac{4 \pi}{Q} \mathrm{KT}$

$$
\text { Stress: } \quad \Sigma=4 \pi \frac{K(1-\nu)}{\alpha E} \frac{\sigma}{Q}
$$

We shall also introduce the two dimensionless ralius $R-r^{2} / r_{2}{ }^{2}$ and $R_{1}=r_{1}{ }^{2} / r_{2}{ }^{2}$. The previous equations now read:

* Refer to Bonilla: Nuclear Engineering, McGraw, Hill Chapter 11. 


$$
\begin{aligned}
& \Sigma_{r}=\frac{\theta_{a v}}{2}\left(1-\frac{R_{1}}{R}\right)-\frac{1}{2 R} \int_{R_{1}}^{R} \theta d R \\
& \Sigma_{\theta}=\frac{\theta_{a v}}{2}\left(1+\frac{R_{1}}{R}\right)+\frac{1}{2 R} \int_{R_{1}}^{R} \theta d R-\theta \\
& \Sigma_{Z}=\Sigma_{r}+\Sigma_{\Theta}=\theta_{a v}-\theta
\end{aligned}
$$

It is easy to see that the largest tensile axial stress occurs at the coolest surface

$$
\left(\Sigma_{Z}\right)_{s}=\theta_{\text {av }}-\theta_{s}
$$

and that the largest compressive axial stress corresponds to the maximum fuel temperature

$$
\left(-\Sigma_{z}\right)_{\max }=\theta_{\mathrm{m}}-\theta_{\mathrm{av}}
$$

Since $\Sigma_{r}=0$ for $R=R_{1}$ and $R=1$ (by assumption) we find that at both boundaries $\left(\Sigma_{\Theta}\right)_{s}=\left(\Sigma_{Z}\right)_{s}=\theta_{\text {av }}-\theta_{s}$

By definition, we have

$$
\theta_{\mathrm{av}}=\frac{1}{1-\mathrm{R}_{1}} \int_{\mathrm{R}_{1}}^{1} \theta d R
$$

In order to find the elastic thermal stresses, let us write the temperature distribution (Eq. 15) in dimensionless form, with $\mathrm{p}=\mathrm{H} / \mathrm{H}_{\mathrm{av}}$ 


$$
\theta-\theta_{2}=\left(\frac{\theta_{1}-\theta_{2}}{\ln R_{1}}\right) \ln R+\frac{1}{\left(1-R_{1}\right)} \iint_{R}^{1} p \ln \left(\frac{R}{R}\right) d^{-}+\frac{\ln R}{\ln R_{1}} \int_{R_{1}}^{1} p \ln R^{-} d^{-} R_{C-12}
$$

From the definition of $\mathrm{J}$ (Eq. 22), we have

$$
\int_{R_{1}}^{1} p \ln R^{-} d^{-}=-2 J\left(1-R_{1}\right)
$$

and therefore Eq. $(\mathrm{C}-12)$ reads:

$$
\theta-\theta_{2}=\left(\frac{\theta_{1}-\theta_{2}-2 J}{\ln R_{1}}-1\right) \ln R+\frac{1}{\left(1-R_{1}\right)} \int_{R}^{1} p \ln \left(\frac{R}{R}\right) d^{-}
$$

which could also be written,

$$
\theta-\theta_{2}=\left(\theta_{1}-\theta_{2}\right) \frac{\ell n R}{\ell n R_{1}}-\frac{2 J}{\ell n R_{1}} \ln \left(\frac{R}{R_{1}}\right)+\frac{1}{\left(1-R_{1}\right)} \int_{R_{1}}^{R} p \ln \left(\frac{R^{-}}{R}\right) d R^{-} \quad C-14
$$

(which is the same as Eq. 32).

We can therefore calculate the expression in Eq. C-6 and C-7:

$\int_{R_{1}}^{R}\left(\theta-\theta_{2}\right) d R=2 J\left(R-R_{1}\right)+\frac{\theta_{1}-\theta_{2}-2 J}{\ell n R_{1}}\left[R(\operatorname{lnR}-1)-R_{1}\left(\ell n R_{1}-1\right)\right]$

$$
+\frac{1}{\left(1-R_{1}\right.}\left\{R \int_{R_{1}}^{R} p\left(1+\ell n_{\frac{R}{R^{-}}}^{R^{-}}\right) d R^{-}-\int_{R_{1}}^{R} R^{-} p d R^{-}\right\}
$$

and also, since $L=\int_{R_{1}}^{1} R p d R / 2\left(1-R_{1}\right)^{2}$ 


$$
\Theta_{\mathrm{av}}-\Theta_{2}=-\left(\Theta_{1}-\Theta_{2}\right)\left(\frac{1}{\ln \mathrm{R}_{1}}+\frac{\mathrm{R}_{1}}{1-\mathrm{R}_{1}}\right)+\frac{1}{\left(1-\mathrm{R}_{1}\right)}+\frac{2 \mathrm{~J}}{\ln \mathrm{R}_{1}}-2 \mathrm{~L}
$$

(same as Eq. 30).

Expressions (C-15 and C-16) could therefore be introduced in Eq. (C-6) for the distribution of radial stress

$$
\begin{aligned}
& \Sigma_{r}=\frac{1}{2}\left[1-\frac{R_{1}}{R}\right]\left\{-\left(\theta_{1}-\theta_{2}\right)\left(\frac{1}{\ln R_{1}}+\frac{R_{1}}{1-R_{1}}\right)+\frac{1}{\left(1-R_{1}\right)}+\frac{2 J}{\ln R_{1}}-2 \mathrm{~L}\right\} \\
& -\frac{1}{2}\left\{2 J\left(R-R_{1}\right)+\frac{\Theta_{1}-\theta_{2}-2 J}{\ell n R_{1}}\left[R(\ln R-1)-R_{1}\left(\ln R_{1}-1\right)\right]\right. \\
& +\frac{1}{\left(1-R_{1}\right)}\left[R \int_{R_{1}}^{R} p\left(1+\ln \frac{R^{-}}{R}\right) d R^{-}-\int_{R_{1}}^{R} R^{-} p d R^{-}\right] \mid
\end{aligned}
$$

which is now a function of $R$ with $\left(\theta_{1}-\theta_{2}\right)$ and $R_{1}$ as parameters (for a given power distribution $\mathrm{p}$ ).

Recall that we have already derived an expression for $\theta$ (Eq. C-14); therefore the axial stress reads (Eq. C-8).

$$
\begin{aligned}
& \Sigma_{Z}=\left(\theta_{\mathrm{av}}-\theta_{2}\right)-\left(\theta-\theta_{2}\right) \\
& =-\left(\theta_{1}-\theta_{2}\right)\left(\frac{1}{\ln R_{1}}+\frac{R_{1}}{1-R_{1}}\right)+\frac{1}{\left(1-R_{1}\right)}+\frac{2 J}{\ell n R_{1}}-2 L \\
& \left.-\left(\theta_{1}-\theta_{2}\right) \frac{\ln R}{\ln R_{1}}+\frac{2 J}{\ln R_{1}} \ln \left(\frac{R}{R_{1}}\right)-\frac{1}{\left(1-R_{1}\right.}\right) \int_{R_{1}}^{R} p \ln \left(\frac{R^{-}}{R}\right) d R^{-} \quad C-18
\end{aligned}
$$

Finally, the tangential stress is derived from Eq. (C-3):

$$
\Sigma_{\theta}=\Sigma_{Z}-\Sigma_{\mathbf{r}}
$$


Eq. (C-17) could be somewhat simplified

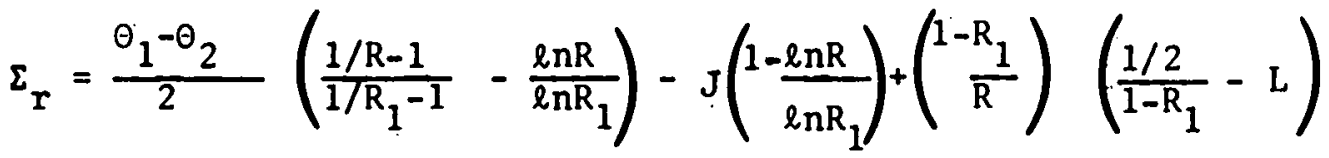

$$
\begin{aligned}
& -\frac{1}{2\left(1-R_{1}\right)} \iint_{R_{1}}^{B} p\left[1+\ell n\left(\frac{R^{\prime}}{R}\right)\right] d R^{-}-\frac{1}{R} \int_{R_{1}}^{R} R^{\prime} p d R^{-} \mid
\end{aligned}
$$

and similarly, eq. (C-18) and(C-19) could be written:

$$
\begin{aligned}
& \Sigma_{Z}=-\left(\theta_{1}-\theta_{2}\right)\left(\frac{1}{1 / R_{1}-1}+\frac{1+\ell n R}{\ell n R_{1}}\right)+\frac{1}{1-R_{1}}-2 L+2 J\left(\frac{1+\ell n R}{\ell n R_{1}}-1\right)-\frac{1}{\left(1-R_{1}\right)} \int_{R_{1}}^{R} p \ell n\left(\frac{R^{\prime}}{R}\right) d R^{\prime} \\
& \Sigma_{\Theta}=-\frac{\theta_{1}-\theta_{2}}{2}\left(\frac{1 / R+1}{1 / R_{1}-1}+\frac{2+\ln R}{\ln R_{1}}\right)+J\left(\frac{2+\ln R}{\ln R_{1}}-1\right)+\left(1+\frac{R_{1}}{R}\right)\left(\frac{1 / 2}{1-R_{1}}-L\right) \\
& -\frac{1}{2\left(1-R_{1}\right)}\left|\int_{R_{1}}^{R} p\left[\ln \left(\frac{R^{-}}{R}\right)-1\right] d R^{-}+\frac{1}{R} \int_{R_{1}}^{R} R^{\prime} p d R^{-}\right|
\end{aligned}
$$

In the case of uniform power density $p=1$ and we found

$$
L=\frac{1+R_{1}}{4\left(1-R_{1}\right)} \quad \text { and } J=\frac{1}{2}\left(1+\frac{\ell n R_{1}}{1 / R_{1}-1}\right)
$$

Therefore the previous expression for $\Sigma_{r}$ becomes

$$
\Sigma_{r}=\frac{\Theta_{1}-\Theta_{2}}{2}\left(\frac{1 / R-1}{1 / R_{1}-1}-\frac{\ell n R}{\ell n R_{1}}\right)+\frac{1}{4}\left(1-\frac{R_{1}}{R}\right) \frac{1+R}{1-R_{1}}-\frac{1}{2}\left(1-\frac{\ell n R}{\ell n R_{1}}\right)
$$

or

$$
\Sigma_{r}=\frac{\theta_{1}-\theta_{2}}{2}\left(\frac{1 / R-1}{1 / R_{1}-1}-\frac{\ln R}{\ln R_{1}}\right)-\frac{1}{2}\left\{\frac{1 / R-1}{1 / R_{1}-1} \frac{R / R_{1}+1}{2}-\frac{\operatorname{lnR}}{\ln R_{1}}\right\}
$$


Finally, the radial stress reads:

$$
\Sigma_{r}=\frac{1-\left(\theta_{1}-\theta_{2}\right)}{2}\left(\frac{\ln R}{\ln R_{1}}-\frac{1 / R-1}{1 / R_{1}-1}\right)-\frac{\left(R-R_{1}\right)(1-R)}{4 R\left(1-R_{1}\right)}
$$

Similarly, the axial and tangential stresses may be written:

$$
\begin{aligned}
& \Sigma_{Z}=\frac{1}{2}-\frac{1-R}{1-R_{1}}+\left[1-\left(\theta_{1}-\Theta_{2}\right)\right]\left(\frac{1}{1 / R_{1}-1}+\frac{1+\ln R}{\ln R_{1}}\right) \\
& \Sigma_{\Theta}=\frac{1}{2}-\frac{1-R}{1-R_{1}}\left(1-\frac{R-R_{1}}{4 R}\right)+\frac{1}{2}\left[1-\left(\theta_{1}-\theta_{2}\right)\right]\left(\frac{1 / R+1}{1 / R_{1}-1}+\frac{2+\ln R}{\ln R_{1}}\right)
\end{aligned}
$$

Notice that the dimensionless temperatures now read:

$$
\begin{aligned}
& \theta-\theta_{2}=-\left[1-\left(\theta_{1}-\theta_{2}\right)\right] \frac{\ln R}{\ln R_{1}}+\frac{1-R}{1-R_{1}} \\
& \theta_{a v}-\theta_{2}=\frac{1}{2}+\left[1-\left(\theta_{1}-\theta_{2}\right)\right]\left(\frac{1}{\ln R_{1}}+\frac{1}{1 / R_{1}-1}\right)
\end{aligned}
$$

At the inner surface $\left(R=R_{l}\right)$, we find

$$
\left(\Sigma_{\theta}\right)_{1}=\left(\Sigma_{Z}\right)_{1}=-\frac{1}{2}+\left(\frac{1}{\ln R_{1}}+\frac{1}{1-R_{1}}\right) \cdot\left[1-\left(\theta_{1}-\theta_{2}\right)\right]
$$

While at the outer surface $(R=1)$

$$
\left(\Sigma_{\theta}\right)_{2}=\left(\Sigma_{Z}\right)_{2}=\left(\frac{1}{\ln R_{1}}+\frac{1}{1 / R_{1}-1}\right)\left[1-\left(\theta_{1}-\theta_{2}\right)\right]+\frac{1}{2}
$$

These last two expressions could also be written

$$
\begin{aligned}
& \left(\Sigma_{\Theta}\right)_{1}=\left(\Sigma_{Z}\right)_{1}=\frac{1}{2}\left[\frac{2}{\ln R_{1}}+\frac{1+R_{1}}{1-R_{1}}\right]-\left(\theta_{1}-\theta_{2}\right)\left(\frac{1}{\ln R_{1}}+\frac{1}{1-R_{1}}\right) \\
& \left(\Sigma_{\theta}\right)_{2}=\left(\Sigma_{Z}\right)_{2}=\frac{1}{2}\left[\frac{2}{\ln R_{1}}+\frac{1+R_{1}}{1-R_{1}}\right]-\left(\theta_{1}-\theta_{2}\right)\left(\frac{1}{\ln R_{1}}+\frac{1}{1-R_{1}}\right)
\end{aligned}
$$


We find, as expected, that the stresses at the surface are equal when the surface temperatures are equal, since $\left(\Sigma_{z}\right)_{2}-\left(\Sigma_{z}\right)_{1}=\theta_{1}-\theta_{2}$, and that the largest tensile stress occurs at the coolest surface.

When the inside boundary is insulated (external cooling), the largest tensile stress occurs at the outer boundary

$$
\left(\Sigma_{z}\right)_{2}=\theta_{a v}{ }^{-} \Theta_{2}=\frac{1}{2}-\frac{R_{1}}{1-R_{1}}\left(1+\frac{R_{1} \ell n R_{1}}{1-R_{1}}\right)
$$

While for internal cooling, the largest tensile stress occurs at the inner boundary:

$$
\left(\Sigma_{2}\right)_{1}=\theta_{a v^{-} \theta_{1}}=-\frac{1}{2}-\frac{1}{1-R_{1}}\left(1+\frac{\ell n R_{1}}{1-R_{1}}\right)
$$

We have already found these expressions in Table $I$ and have plotted them on Fig. 6 where it is seen that the stress with internal cooling is higher than the stress with external cooling which is itself higher than with cooling on both sides and with the same surface temperature:

$$
\left.\left(\Sigma_{z}\right)_{1}=\left(\Sigma_{z}\right)_{2}=\frac{1}{\ell n R_{1}}+\frac{1}{2} \frac{1+R_{1}}{1-R_{1}} \quad \text { (when } \theta_{1}=\theta_{2}\right)
$$

We notice that the dimensionless stresses depend upon three parameters:

$$
R=r^{2} / r_{2}^{2}, \quad R_{1}=r_{1}^{2} / r_{2}^{2} \text { and } 1-\left(\theta_{1}-\theta_{2}\right)=1-\frac{4 \pi K}{Q} \cdot\left(T_{1}-T_{2}\right)
$$

We find that $\left(\frac{1}{\ln R_{1}}+\frac{1}{1-R_{1}}\right) \geq 0$ and $\left(\frac{1}{\ln R_{1}}+\frac{R_{1}}{1-R_{1}}\right) \leq 0$, and also that:

$$
\left(\Sigma_{Z}\right)_{1}=0 \text { when: } \theta_{1}-\theta_{2}=\frac{\frac{1}{\ln R_{1}}+\frac{1+R_{1}}{2\left(1-R_{1}\right)}}{\frac{1}{\ln R_{1}}+\frac{1}{1-R_{1}}}(\geq 0)
$$


and $\left(\Sigma_{2}\right)_{2}=0$ when $\theta_{2}-\theta_{1}=\frac{\frac{1}{\operatorname{lnR} 1}+\frac{1+R_{1}}{2\left(1-R_{1}\right)}}{-\left(\frac{1}{\ln R_{1}}+\frac{R_{1}}{1-R_{1}}\right)}(\geq 0)$

The minimum value of $\Sigma_{Z}$ corresponding to the maximum compressive axial stress occurs at the location of the maximum temperature given by the relation (see $\mathrm{Eq} . \mathrm{A}-2$ )

$$
R_{m}=-\frac{1-R_{1}}{\ln R_{1}}\left[1-\left(\Theta_{1}-\theta_{2}\right)\right]
$$

and this stress reads:

$$
\begin{aligned}
\left(-\Sigma_{Z}\right)_{\max } & =\frac{1}{2} \frac{1+R_{1}}{1-R_{1}}-\left[1-\left(\theta_{1}-\theta_{2}\right)\right]\left(\frac{1}{1 / R_{1}-1}+\frac{\ell n R_{m}}{\ln R_{1}}\right) \\
\text { or }\left(-\Sigma_{Z}\right)_{\max } & =\frac{1}{\left(1-R_{1}\right)}\left\{\frac{1+R_{1}}{2}+R_{m} l n_{1}\left(\frac{1}{1 / R_{1}-1}+\frac{\ell n R_{m}}{\ell n R_{1}}\right)\right\}
\end{aligned}
$$

When either surface is insulated, the maximum temperature occurs at the insulated surface which also corresponds to the maximum compressive axial stress

$$
\left(-\Sigma_{Z}\right)_{\max }=\frac{1}{\left(1-\mathrm{R}_{1}\right)}\left(\frac{1+\mathrm{R}_{1}}{2}+\frac{\mathrm{R}_{1} \ell \mathrm{nR}_{1}}{1-\mathrm{R}_{1}}\right)
$$

While, for equal surface temperatures:

$$
\left(-\Sigma_{Z}\right)_{\max }=\frac{1}{2}-\frac{1}{\operatorname{lnR}_{1}} \ln \left(-\frac{1-R_{1}}{\ell n R_{1}}\right)
$$

(See Table I)

Let us recall that, Since $R_{1} \leq R_{m} \leq 1$, we have found the conditions:

$$
1+\frac{\ln \mathrm{R}_{1}}{1-\mathrm{R}_{1}} \leq\left(\theta_{1}-\theta_{2}\right) \leq 1+\frac{\mathrm{R}_{1} \ln \mathrm{R}_{1}}{1-\mathrm{R}_{1}}
$$


The extremum values of the dimensionless radial stress $\Sigma_{r}$ may be obtained by differentiating Eq. (C-24), which gives a quadratic equation for $R$ :

$$
R^{2}+2 \frac{1-R_{1}}{\ln R_{1}}\left[1-\left(\Theta_{1}-\Theta_{2}\right)\right] R+R_{1}\left[1-2\left(\theta_{1}-\theta_{2}\right)\right]=0
$$

We shall substitute from Eq. (C-31)

$$
-\frac{1-R_{1}}{\ln R_{1}}\left[1-\left(\theta_{1}-\theta_{2}\right)\right]=R_{m}
$$

and the previous equation reads simply

$$
R^{2}-2 R R_{m}-R_{1}\left(1+2 R_{m} \frac{\ell n R_{1}}{1-R_{1}}\right)=0
$$

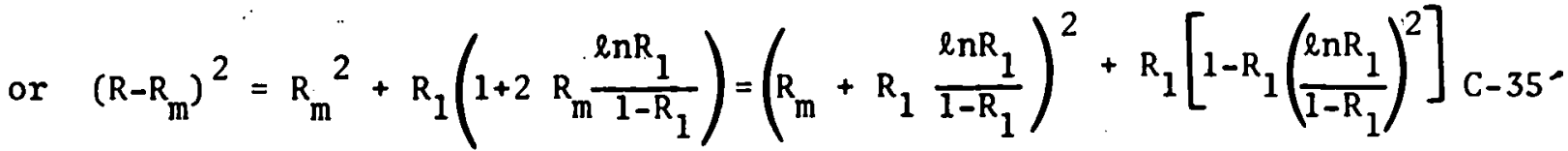
We find two positive roots $R^{-}{ }_{1}$ and $R^{-}{ }_{2}$ such that

$$
R_{1} \leq R_{1}^{\circ} \leq R_{m} \leq R_{2}^{-} \leq 1
$$

We find that both $\Sigma_{r}^{\prime}\left(R_{1}\right)$ and $\Sigma^{\prime}{ }_{r}(1)$ are non negative since

$$
\begin{aligned}
& \Sigma_{r}^{-}\left(R_{1}\right)=\frac{1}{4 R_{1}}\left[-2 \frac{R_{m}}{1-R_{1}}\left(1+\frac{\ell n R_{1}}{1-R_{1}}\right)-1\right] \\
& \Sigma_{r}^{\prime}(1)=\frac{1}{4}\left[1-\frac{2 R_{m}}{1-R_{1}}\left(1+\frac{R_{1} \ell R_{1}}{1-R_{1}}\right)\right]
\end{aligned}
$$

Therefore $\Sigma_{r}$ has a maximum, goes through zero, and then has a minimum. (Recall that $\Sigma_{r}=0$ at $R=R_{1}$ and $R=1$ by assumption). 
The locations of the extrema of $\Sigma_{r}$ could be written

$$
R^{-}=R_{m}\left\{1 \pm \sqrt{1-\frac{R_{1}}{R_{m}^{2}}\left[1-2\left(\theta_{1}-\theta_{2}\right)\right]}\right\}
$$

A similar derivation could be performed for $\Sigma_{\Theta}$ starting from Eq. (C-26): we could also use the expression $\Sigma_{\theta}=\Sigma_{Z}-\Sigma_{r}$ with the previous results.

$$
\text { For equal surface temperatures, } \theta_{1}=\theta_{2} \text { and } R_{m}=-\frac{1-R_{1}}{\ell n R_{1}}
$$

Equation (C-36) for the location of the extrema reads

$$
R=R_{m}\left(1+\varepsilon \sqrt{1-R_{1} / R_{m}^{2}}\right)
$$$$
\varepsilon= \pm 1
$$

and the values of the maximum and minimum radial stresses may be easily derived since we now have:

$$
\Sigma_{r}=\frac{1}{2}\left\{\frac{\ln R}{\ln R_{1}}-\frac{1-R}{2\left(1-R_{1}\right)}\left(1+\frac{R_{1}}{R}\right)\right\}
$$

Similarly, we now find for the axial and tangential stresses

$$
\begin{aligned}
& \Sigma_{Z}=\frac{\mathrm{R}}{1-\mathrm{R}_{1}}-\frac{1}{2}+\frac{1+\ell \mathrm{nR}}{\ln \mathrm{R}_{1}} \\
& \Sigma_{\Theta}=\frac{1}{2}\left[\frac{2+\ell \mathrm{nR}}{\operatorname{lnR} 1}-\frac{1}{2}+\frac{3 \mathrm{R}+\mathrm{R}_{1} / \mathrm{R}}{2\left(1-\mathrm{R}_{1}\right)}\right]
\end{aligned}
$$

The location of the extremum of the tangential stress $\left(\Sigma_{\Theta}\right)$ is given by

$$
\mathrm{R}^{\infty}=\frac{\mathrm{R}_{\mathrm{m}}}{3}\left(1+\sqrt{1+\frac{3 \mathrm{R}_{1}}{\mathrm{R}_{\mathrm{m}}^{2}}}\right)
$$


We find that $\Sigma^{{ }^{\prime}}{ }_{\theta}\left(R_{1}\right) \leq 0, \Sigma^{{ }^{\circ}}{ }_{\theta}\left(R_{m}\right) \geq 0, \Sigma^{\prime}{ }_{\theta}(1) \geq 0$ and therefore $\Sigma_{\theta}$ has a minimum at $R^{\infty}<R_{m}$ corresponding to the maximum value of the tangential compressive stress which is very close to the maximum value of the axial compressive stress but slightly smaller (in absolute value). We found that

$$
\Sigma_{\Theta}\left(R_{1}\right)=\Sigma_{\theta}(1)=\Sigma_{Z}\left(R_{1}\right)=\Sigma_{Z}(1)=\frac{1}{\ell n R_{1}}+\frac{1}{2} \frac{1+R_{1}}{1-R_{1}}
$$

and, as always, $\Sigma_{r}\left(R_{1}\right)=\Sigma_{r}(1)=0$.

We have plotted on Fig. (20) the three thermal stresses in the case where $R_{1}=1 / 4\left(r_{1} / r_{2}=1 / 2\right)$. We have also shown the dimensionless temperature distribution. We find the maximum dimensionless stresses to be:

$$
\begin{array}{ll}
\text { Tensile: } & \Sigma_{Z}\left(R_{1}\right)=\theta_{a v}-\theta_{s}=0.112 \\
\text { Compressive: } & -\Sigma_{Z}\left(R_{m}\right)=\theta_{m}-\theta_{a v}=0.057
\end{array}
$$

The ratio of these two stresses is close to $1 / 2$ (See also Fig. 4). For $\mathrm{K}_{1} \geq 0.1$, we find $\left(-\Sigma_{Z}\right)_{\max } \cong \frac{1}{2}\left(\Sigma_{Z}\right)_{\max }$

The maximum dimensionless temperature, $\theta_{m}-\theta_{S}=0.168$ is reached for $R_{m}=0.54$.

We find $-\Sigma_{\theta}\left(R^{-\rho}\right) \cong 0.055$ very close to $-\Sigma_{Z}\left(R_{m}\right)$. Fig. (21) shows the locations of the maximum compressive stresses, tangential and axial, and their ratio.

Let us finally remark that the dimensionless temperature distribution given by Eq. (C-27) may be written as a function of the 2 parameters, $\mathrm{R}_{1}\left(=\mathrm{r}_{1}{ }^{2} / \mathrm{r}_{2}^{2}\right)$ and also 


$$
\begin{aligned}
& \frac{r_{m}^{2}}{r_{2}^{2}}=R_{m}=-\frac{1-R_{1}}{\ell n R_{1}}\left[1-\left(\theta_{1}-\theta_{2}\right)\right] \\
& \theta-\theta_{2}=\frac{1-R+R_{m} \ell n R}{1-R_{1}}
\end{aligned}
$$

with $R_{1} \leq R_{m} \leq 1 \quad$ (and, of course, $R_{1} \leq R \leq 1$ )

$R_{m}=R_{1}$ corresponds to inner insulation (external cooling),

$R_{m}=1$ corresponds to outer insulation (inner cooling)

$R_{m}=-\frac{1-R_{1}}{\ell n R_{1}}$ corresponds to equal surface temperatures.

The maximum and average temperatures read respectively:

$$
\begin{aligned}
& \Theta_{m}-\theta_{2}=\frac{1-R_{m}+R_{m} \ell n R_{m}}{1-R_{1}} \\
& \Theta_{a v}-\theta_{2}=\frac{1}{2}\left[1-\frac{2 R_{m}}{1-R_{1}}\left(1+\frac{R_{1} \ell n R_{1}}{1-R_{1}}\right)\right]
\end{aligned}
$$

while the difference between maximum and average temperature reads

$$
\Theta_{m}-\theta_{a v}=\frac{1}{2\left(1-R_{1}\right)}\left\{1+R_{1}+2 R_{m}\left(l n R_{m}+\frac{R_{1} \ell n R_{1}}{1-R_{1}}\right)\right\}
$$

The difference between surface temperatures becomes from Eq. (C-31)

$$
\theta_{1}-\theta_{2}=1+R_{m} \frac{\ell n R_{1}}{1-R_{1}}
$$

Finally the thermal stresses could also be written as functions of $R_{1}$ and $R_{m}$ 


$$
\begin{gathered}
\Sigma_{r}=\frac{1}{2\left(1-R_{1}\right)}\left\{-R_{m} \ln R-\frac{1-R_{1}}{2}+R_{1}\left(\frac{1}{2}+R_{m} \frac{l n R_{1}}{1-R_{1}}\right)\left(\frac{1}{R}-1\right)\right\} \\
\Sigma_{Z}=\frac{1}{2}-\frac{1}{\left(1-R_{1}\right)}\left\{1-R+R_{m}\left(1+R_{1} \frac{l n R_{1}}{1-R_{1}}+\operatorname{lnR}\right)\right\} \\
\Sigma_{\theta}=\frac{1}{2}-\frac{1}{2\left(1-R_{1}\right)}\left\{2 R_{m}+R_{m} \operatorname{lnR}+\frac{3}{2}(1-R)+\frac{R_{1}}{2}\left(\frac{1}{R}-1\right)\right. \\
\left.+R_{m} R_{1} \frac{\ln R_{1}}{1-R_{1}}\left(\frac{1}{R}+1\right)\right\}
\end{gathered}
$$

$\left(R_{1}\right.$ defines the geometry and $R_{m}$ defines the type of cooling.)

The variations of the maximum temperature difference (Eq. C-45), maximum tensile stress (Eq. C-46) and maximum compressive stress (C-47) as functions of the cooling (defined by $R_{m}$ varying between $R_{1}$ and 1 ) could be studied for a given geometry $\left(R_{1}\right)$. For instance Eq. (C-47) for $\left(-\Sigma_{Z}\right)_{\max }$ yields when $R_{m}=R_{1}$ or $R_{m}=1$ (i.e. for an insulated boundary)

$$
\left(-\Sigma_{2}\right)_{\max }=\frac{1}{\left(1-R_{1}\right)}\left(\frac{1+R_{1}}{2}+R_{1} \frac{\ell n R_{1}}{1-R_{1}}\right)=\theta_{m}-\theta_{a v}
$$

$\theta_{m}-\theta_{\text {av }}$ has a minimum with respect to $R_{m}$ (for a given value of $R_{1}$ ) defined by

$$
\ln R_{m}^{*}=-\left(1+\frac{R_{1}{ }^{\ell \cdot n R_{1}}}{1-R_{1}}\right)
$$

or. $\theta_{2}-\theta_{1}=-1-\frac{\ell n R_{1}}{1-R_{1}} \exp \left\{-\left(1+\frac{R_{1} \ell n R_{1}}{1-R_{1}}\right)\right\}$

The value of the minimum of $\left(-\Sigma_{z}\right)_{\max }$ is simply

$$
\frac{1}{\left(1-R_{1}\right)}\left(\frac{1+R_{1}^{\prime}}{2}-R_{m}^{*}\right)
$$


When the surface temperatures are equal, $R_{m}=-\frac{1-R_{1}}{\ell n R_{1}}$ and the corresponding value of $\left(-\Sigma_{Z}\right)_{\max }$ beçomes

$$
\frac{1}{2}+\frac{1}{\ln R_{1}} \ln \left(-\frac{\ln R_{1}}{1-R_{1}}\right)
$$

Figure (22) shows the variations of the maximum compressive stress $\left(-\Sigma_{Z}\right)_{\max }$ versus $R_{m}$ for $R_{1}=1 / 4$. The minimum value of the stress (.0548) is reached at $R_{m}=.584$ when the surface temperatures are nearly equal $\left(R_{m}=.541\right)$ while the largest values (.2172) correspond to one wall insulated. Fig. (23) shows the variations of the normalized maximum compressive stress for a $s l a b$ and for a hollow cylinder with $R_{1}=1 / 4\left(r_{1} / r_{2}=1 / 2\right)$. The smallest value $(0.2514$ at $y=.5284)$ (reached when both surface temperatures are equal for the slab) is very close to $25 \%$ of the largest value (for one insulated boundary). The curve for a hollow cylinder is also very close to the parabola corresponding to the slab.

Fig. 24 shows that the maximum compressive stress has a minimum value which is close to $25 \%$ of its largest value obtained with one insulated boundary; it is smaller than the value of the stress for equal surface temperatures (except for the slab, $r_{1} / r_{2}=1$ ). This minimum stress occurs for $y_{m} \geq 1 / 2$, while for equal surface temperatures, the maximum fuel temperature occurs at $y_{\mathrm{m}} \leq 1 / 2$. The dimensionless surface temperature difference leading to minimum stress (Eq. C-53) is also plotted on Fig. 24. 


\section{LIST OF FIGURES}

1. Location of maximum fuel temperature and ratio of heat fluxes for uniform power density and equal surface temperatures.

2. Maximum and Average Fuel Temperature Drops for uniform power density and external cooling only.

3. Maximum and Average Fuel Temperature Drops for uniform power density and internal cooling only.

4. Maximum and Average Fuel Temperature Drops for uniform power density and equal surface temperatures.

5. Variations of maximum temperature drop for uniform power density with internal cooling, external cooling, or both surfaces at the same temperature.

6. Variations of average temperature drop for uniform power density with internal cooling, external cooling, or both surfaces at the same temperature.

7. Variations of difference between maximum and average temperatures for uniform power density with internal cooling, external cooling, or both surfaces at the same temperature.

8. Comparison of maximum temperature drops and maximum thermal stresses for the same uniform power density with external cooling and with cooling on both sides (with the same surface temperature).

9. Comparison of maximum temperature drops and maximum thermal stresses for the same uniform power density with internal cooling and with cooling on both sides (with the same surface temperature).

10. Comparison of maximum temperature drops and maximum thermal stresses for the same uniform power density with external and internal cooling.

11. Comparison of power densities, and maximum thermal stresses for uniform power density and given maximum fuel temperature drop with external cooling and with cooling on both sides (with the same surface temperature).

12. Comparison of power densities, and maximum thermal stresses for uniform power density and given maximum fuel temperature drop with internal cooling and with cooling on both sides (with the same surface temperature). 
13. Comparison of power densities and maximum thermal stresses for uniform power density and given maximum fuel temperature drop with external and internal cooling.

14. Comparison of power densities, maximum fuel temperature drops, and maximum compressive thermal stresses for uniform power density and given average fuel temperature drop (or maximum tensile thermal stress) with external cooling and with cooling on both sides (with the same surface temperature).

15. Comparison of power densities, maximum fuel temperature drops, and maximum compressive thermal stresses for uniform power density and given average fuel temperature drop (or maximum tensile thermal stress) with internal cooling and with cooling on both sides (with the same surface temperature).

16. Comparison of power densities, maximum fuel temperature drops, and maximum compressive thermal stresses for uniform power density and given average fuel temperature drop (or maximum tensile thermal stress) with external cooling and with internal cooling.

17. Location of the maximum fuel temperature in a cylindrical shell with uniform power density for given difference between surface temperatures.

18. Maximum temperature difference in a cylindrical shell with uniform power density as a function of the relative location of the maximum temperature.

19. Location of the maximum fuel temperature in a cylindrical shell cooled on both sides with uniform power density as a function of the ratio of diameters.

20. Typical dimensionless temperature and stresses distributions for uniform power density and equal surface temperatures.

21. Ratio of maximum compressive axial and tangential stresses and location of these maximum stresses for uniform power density and equal surface temperatures.

22. Variation of maximum compressive stress with location of maximum fuel temperature for uniform power density (and given geometry).

23. Variation of normalized maximum compressive stress versus location of maximum fuel temperature for uniform power density.

24. Variations versus the geometry of the normalized minimum value of the maximum compressive stress and relative location of this minimum for uniform power density. 




Fig. 1. Ratio of heat fluxes and location of maximum fuel temperature versus ratio of radii for equal surface temperatures and uniform power density 




Fig. 2. Maximum, average, and maximum minus average temperature in a cylindrical shell with uniform heat generation when inside wall is insulated (external cooling) 


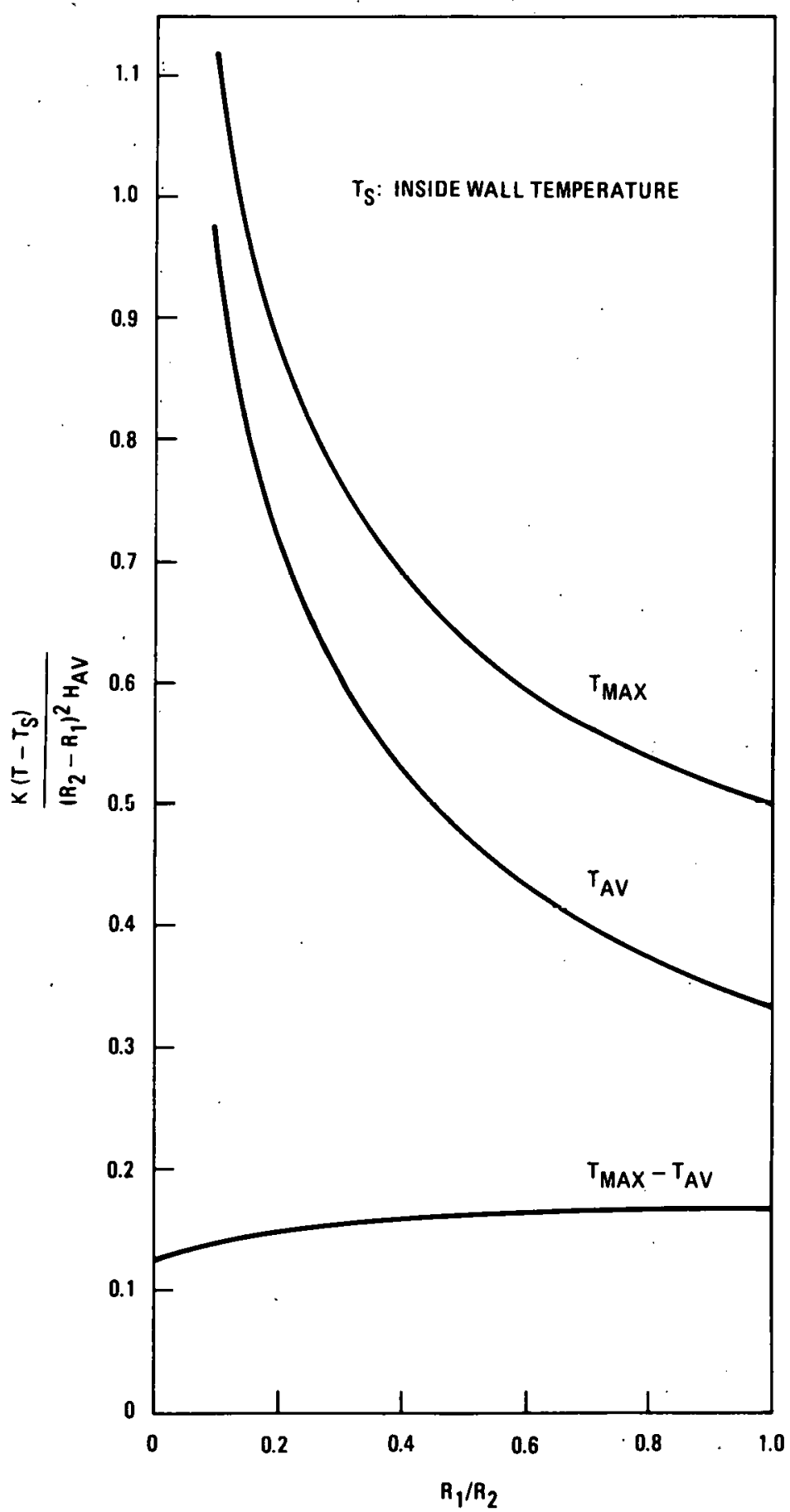

Fig. 3. Maximum, average, and maximum minus average temperaturca in a cylindrical shell with uniform heat generation when outside wall is insulated (internal cooling) 


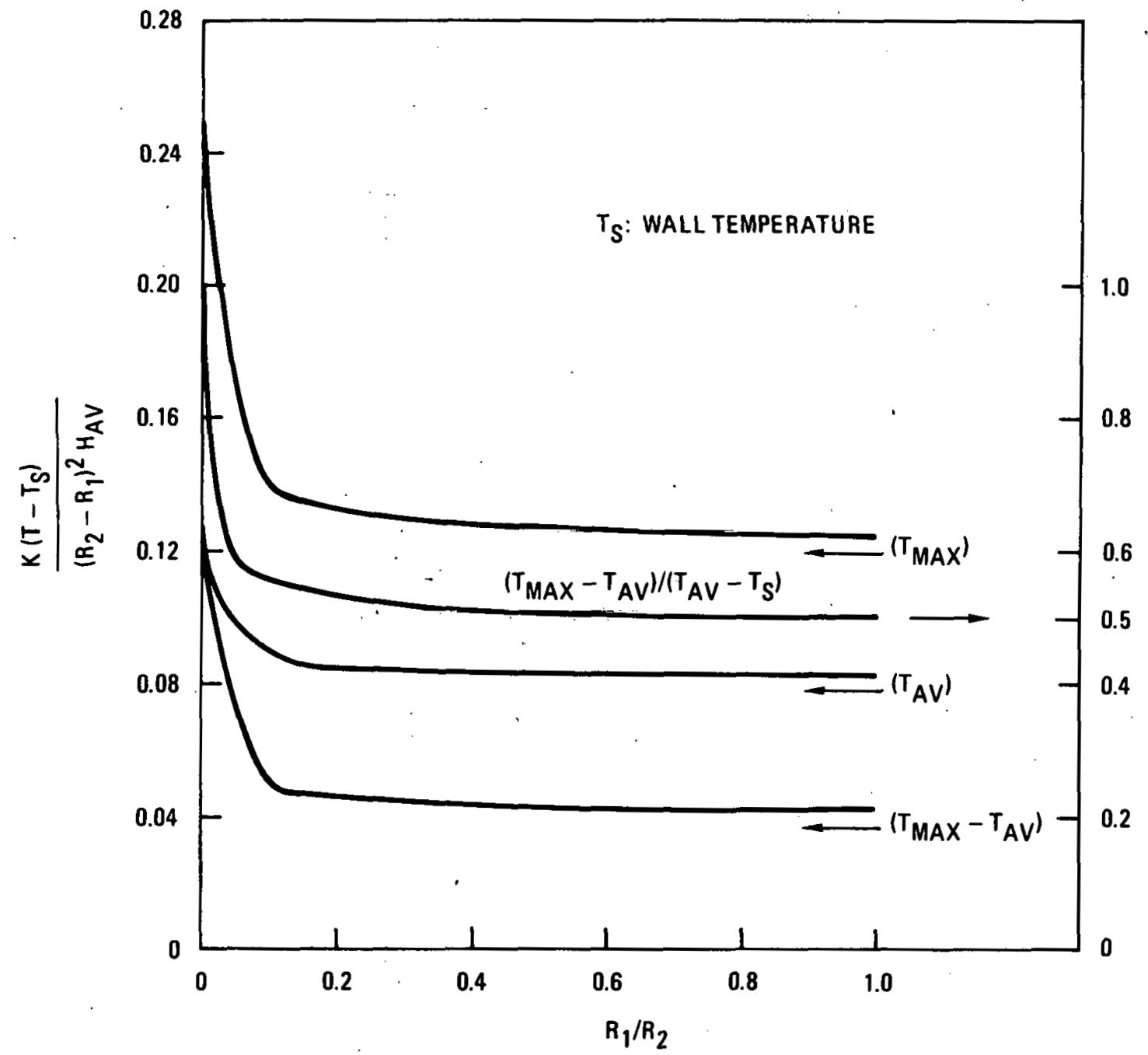

Fig. 4. Maximum, average, and maximum minus average temperatures in a cylindrical shell with uniform heat generation when walls are maintained at the same temperature 




Fig. 5. Variations of maximum temperature drop for uniform power density with internal cooling, external cooling, or both surfaces at the same temperature. 




Fig. 6. Variations of average temperature drop for uniform power density with internal cooling, external cooling, or both surfaces at the same temperature. 


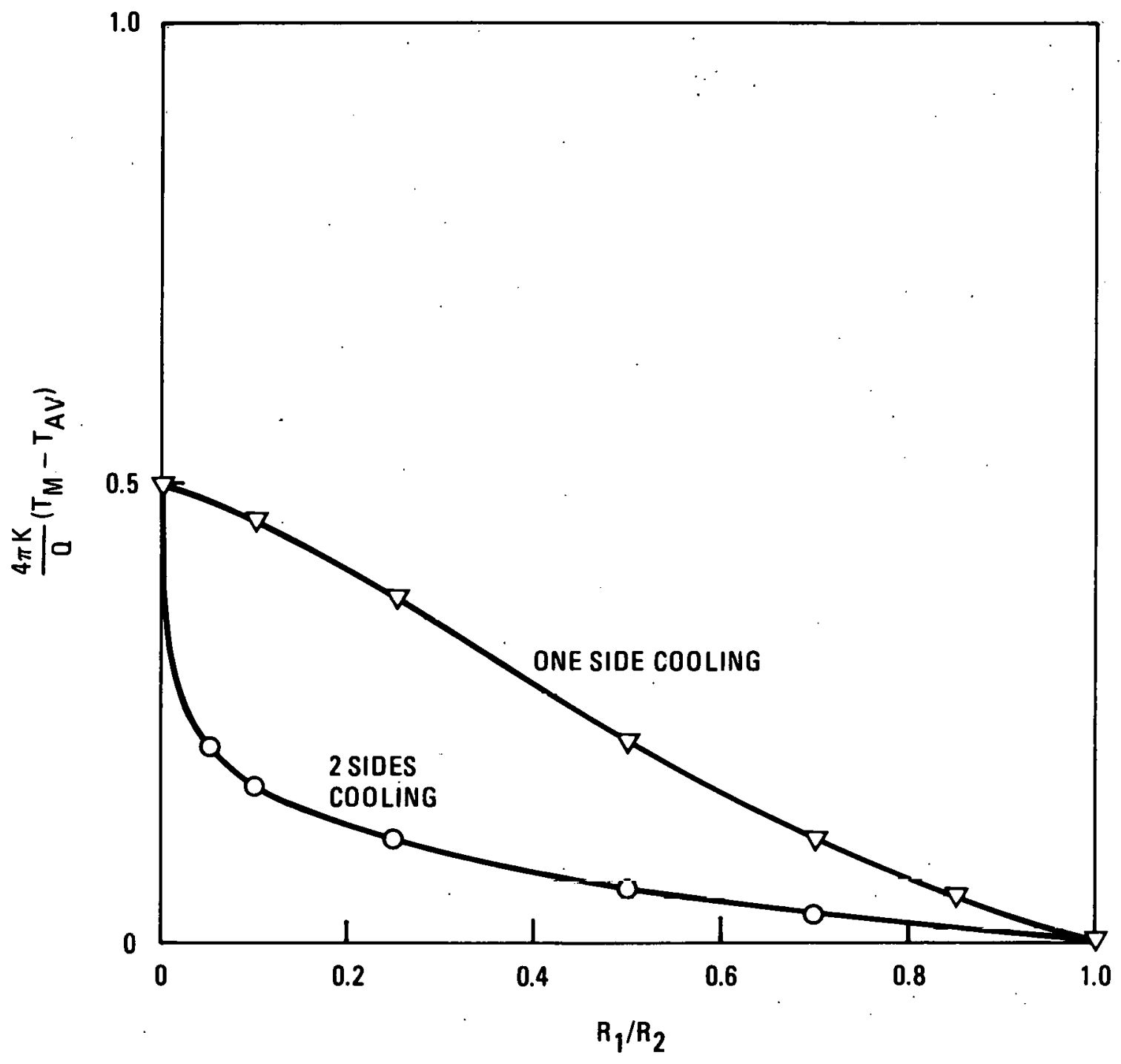

Fig. 7. Variations of difference between maximum and average temperatures for uniform power density with internal cooling, external cooling, or both surfaces at the same temperature. 


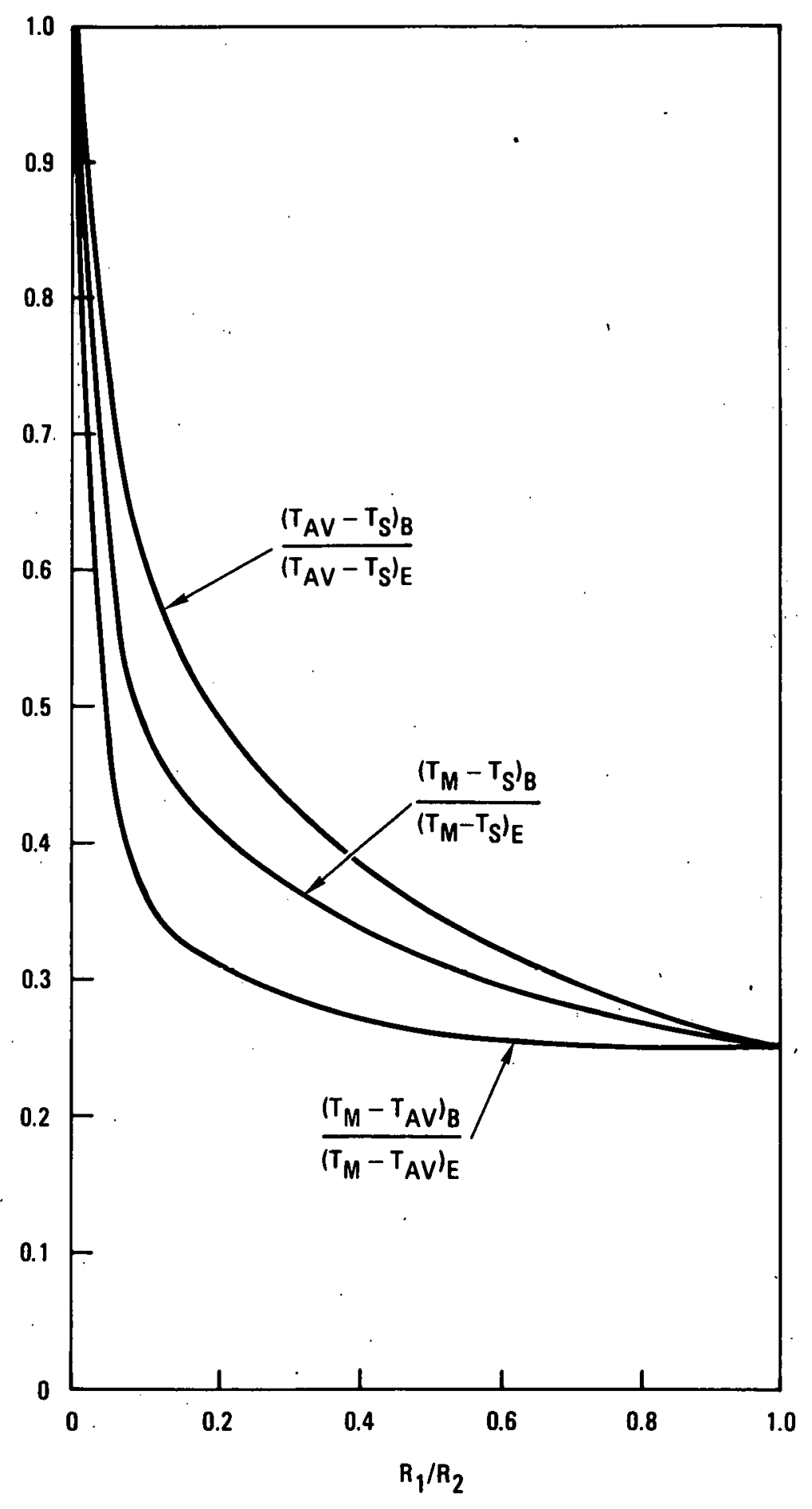

Fig. 8. Comparison of maximum temperature and thermal stresses for cooling on both sides and external cooling of a fuel element for the same uniform power density 


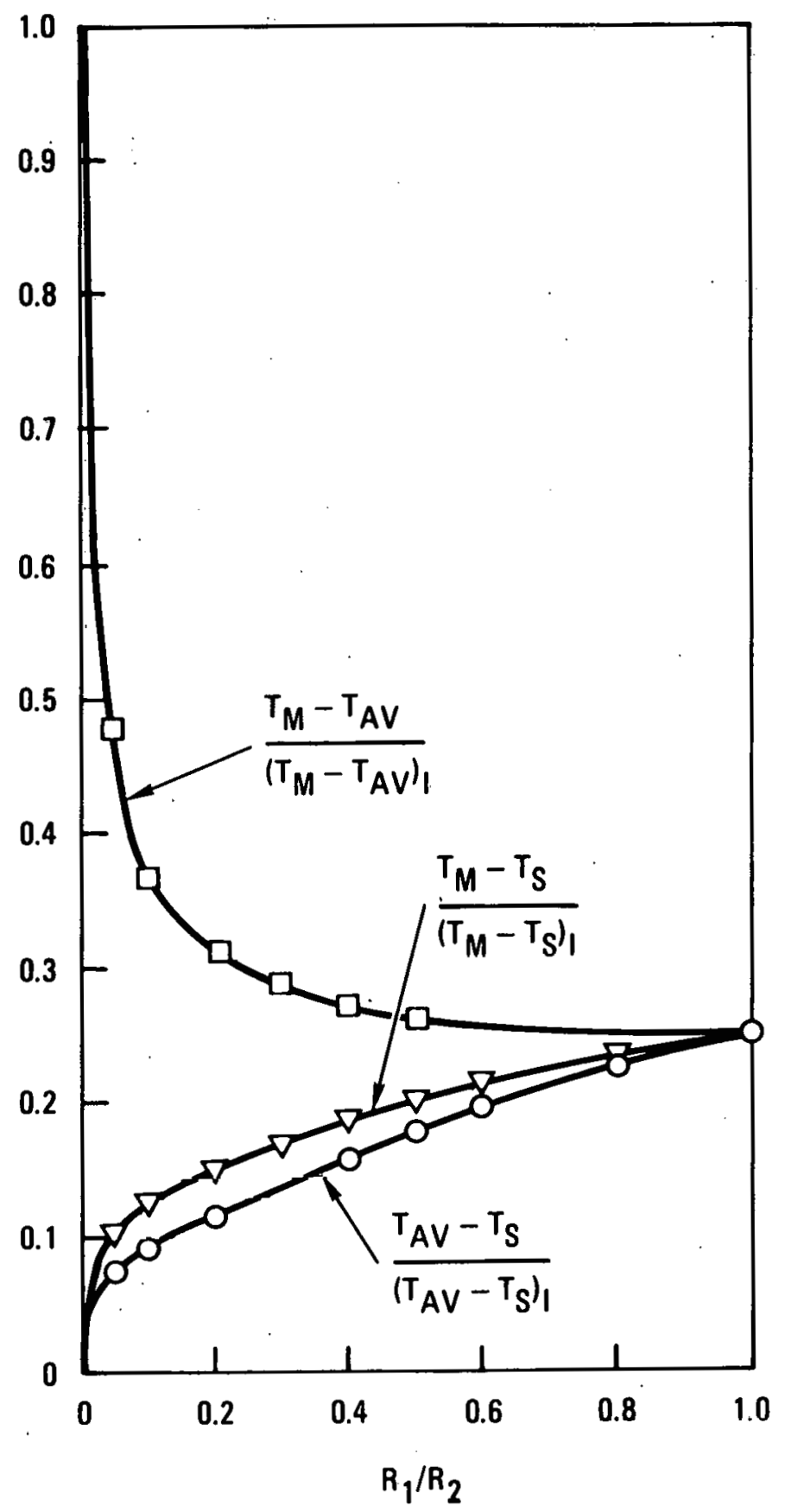

Fig. 9. Comparison of maximum temperature drops and maximum thermal stresses for the same unfform power density with lilternal conling and with cooling on both sides (with the same surface temperature) 


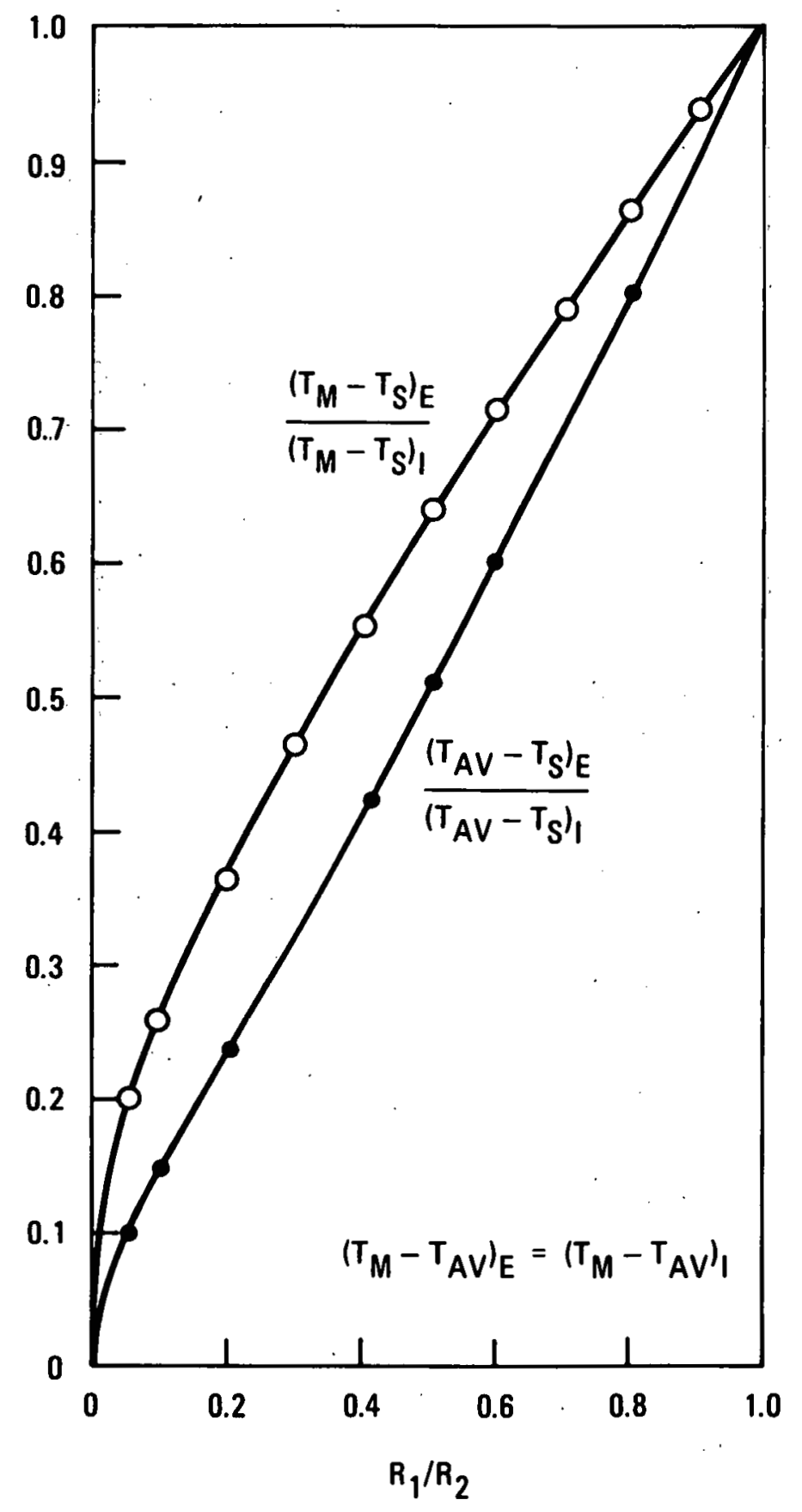

Fig. 10. Comparison of maximum temperature drops and maximum thermal stresses for the same unfform power density with external and internal cooling. 


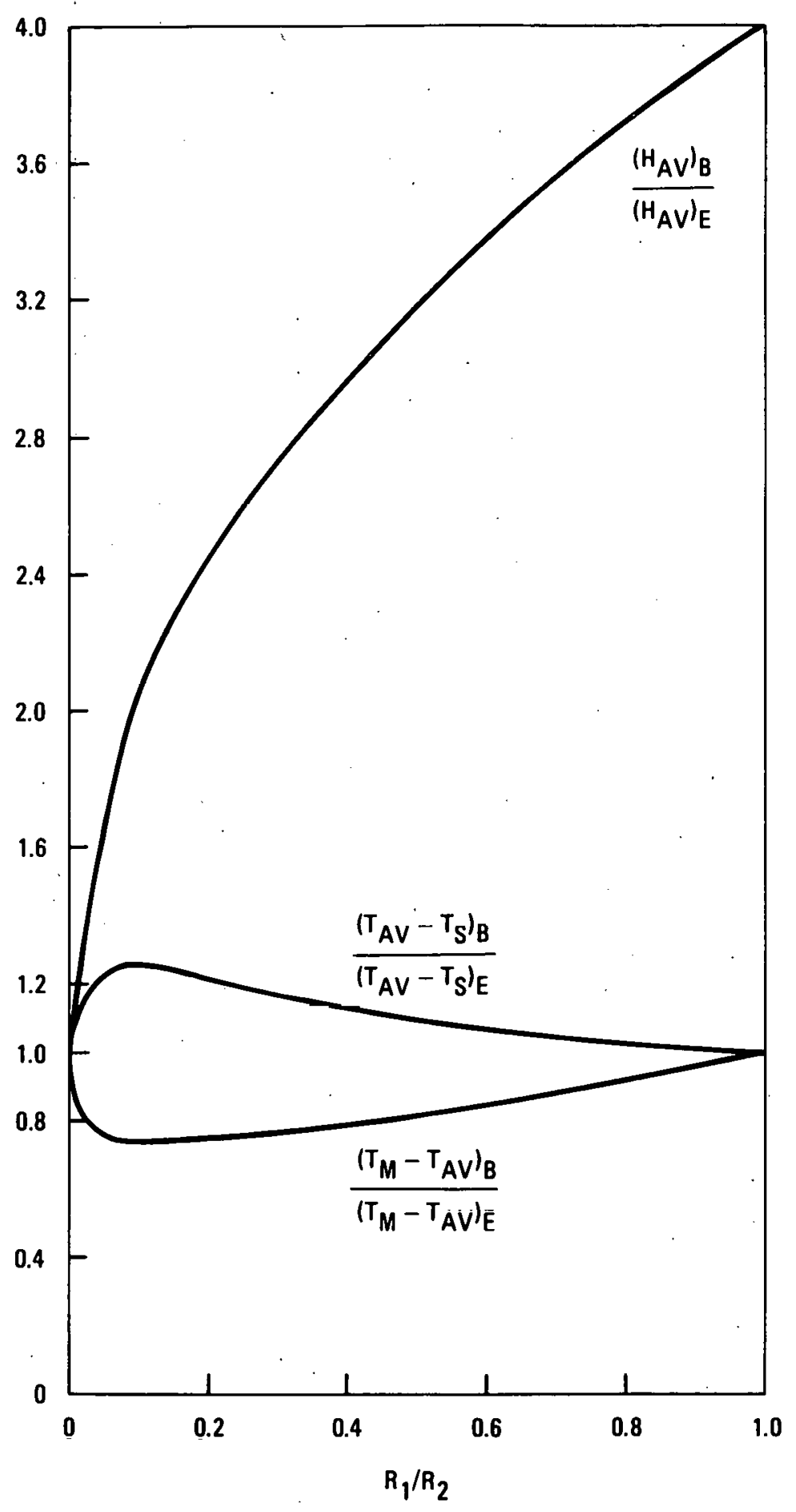

Fig. 11. Ratios of power densities, average temperatures (maximum tensile stresses) and maximum compressive stresses in a cylindrical shell with uniform internal heat generation and given maximum fuel temperature drop in the cases of external cooling and when wa11s are maintained at the same temperature 




Fig. 12. Ratios of power densities, average temperatures (maximum tensile stresses) and maximum compressive stresses in a cylindrical shell with uniform internal heat generation and given maximum fuel temperature drop in the cases of internal cooling and when walls are maintained at the same temperature 


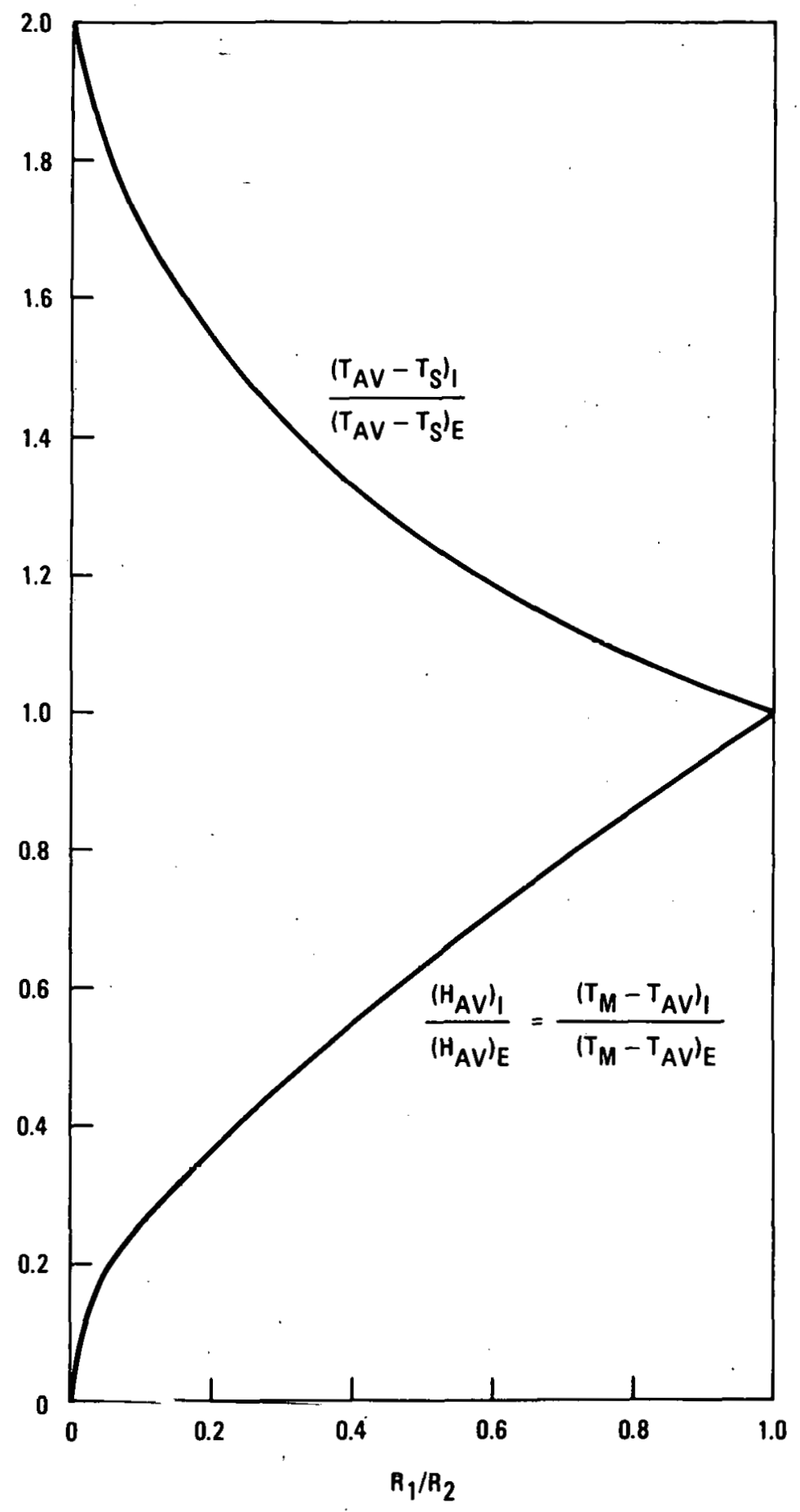

Fig. 13. Ratios of power densities, average temperatures (maximum tensile stresses) and maximum compressive stresses in a cylindrical shell with uniform internal heat generation and given maximum fuel temperature drop in the cases of inner cooling and outer cooling 


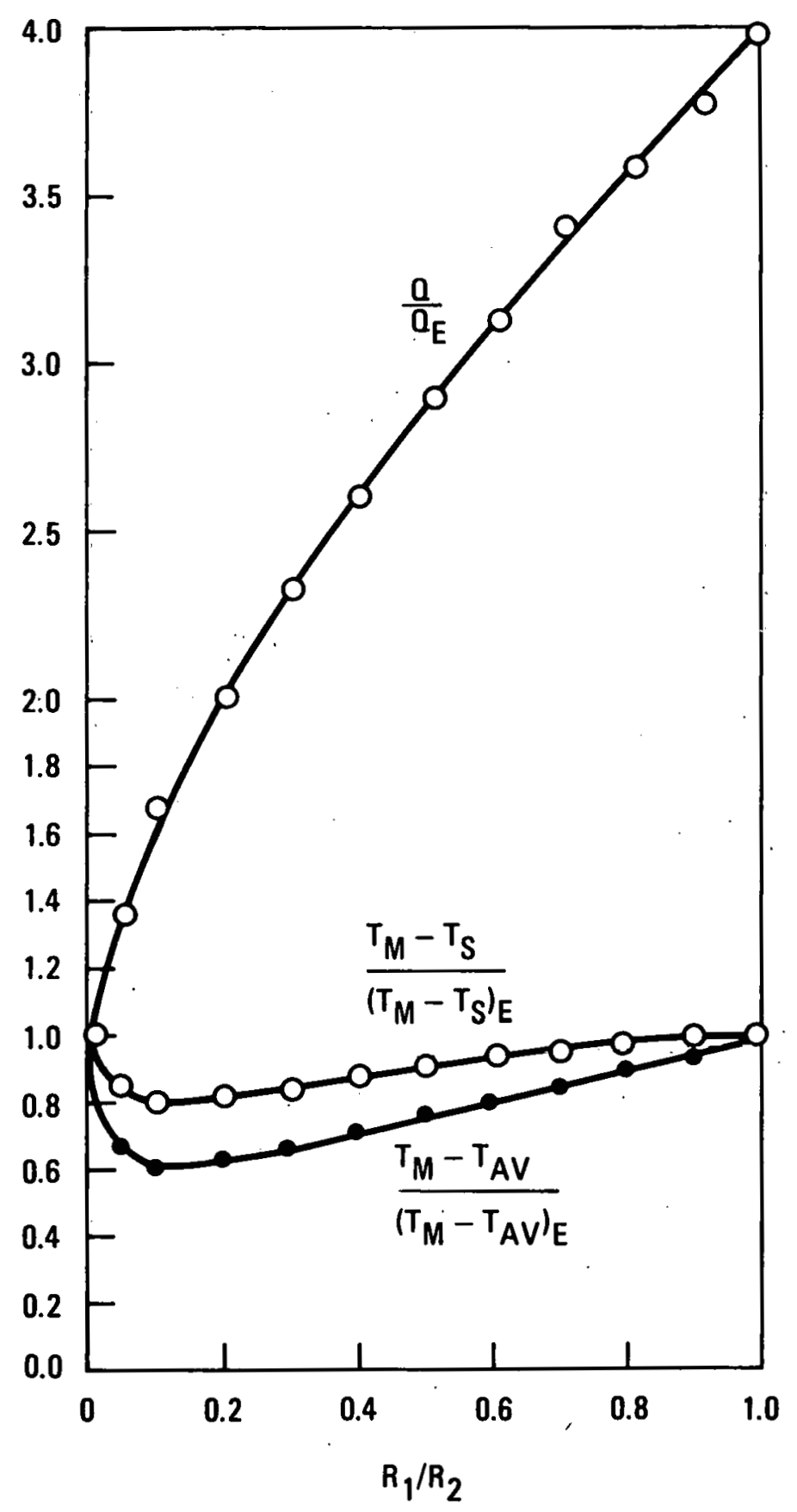

Fig. 14 Comparison of power densities, maximum fuel temperature drops, and maximum compressive thermal stresses for uniform power density and given average fuel temperature drop (or maximum tensile thermal stress) with external cooling and with cooling on both sides (with the same surface temperature) 


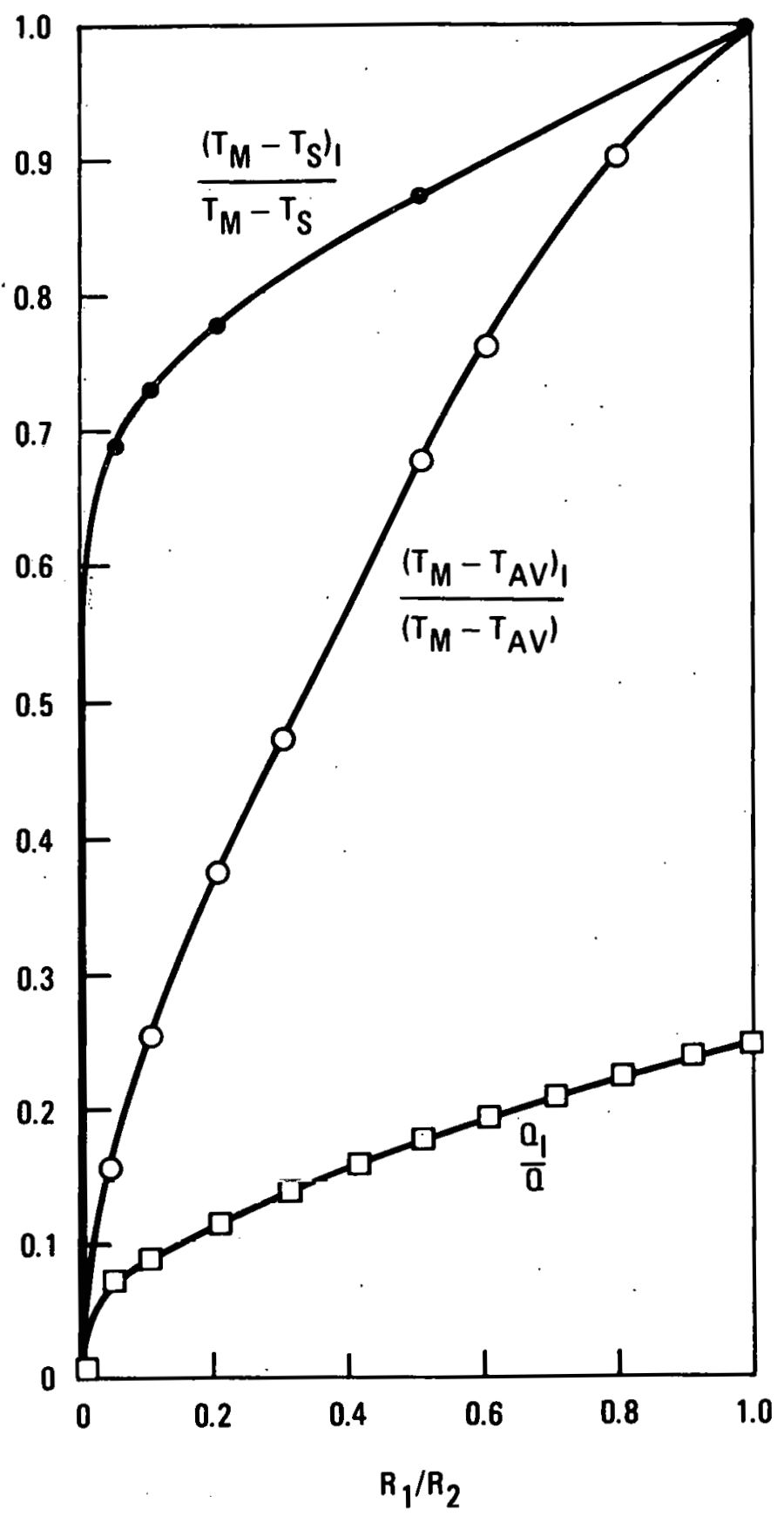

F1g. 15 Comparison of power denstties, maximum fuel temperature drops, and maximum compressive thermal stresses for uriform power density and given average fuel temperature drop (or maximum tensile thermal stress) with internal cooling and with cooling on both sides (with the same surface temperature) 




Fig. 16 Comparison of power densities, maximum fuel temperature drops, and maximum compressive thermal stresses for uniform power density and given average fuel temperature drop (or maximum tensile thermal stress) with external cooling and with internal cooling. 


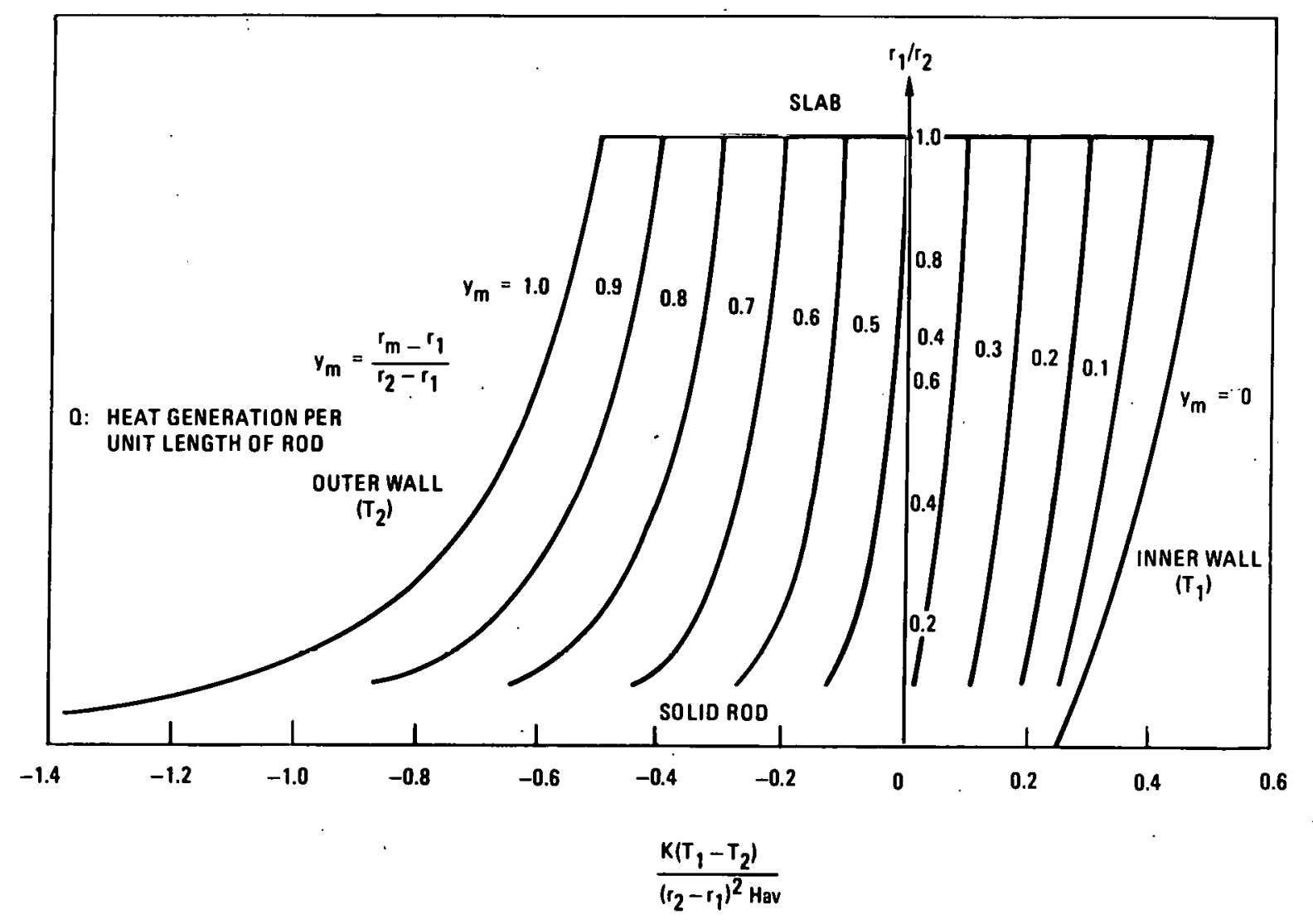

Fig. 17. Location of the maximum temperature in a cylindrical shell with uniform heat generation when the walls temperatures are known. 


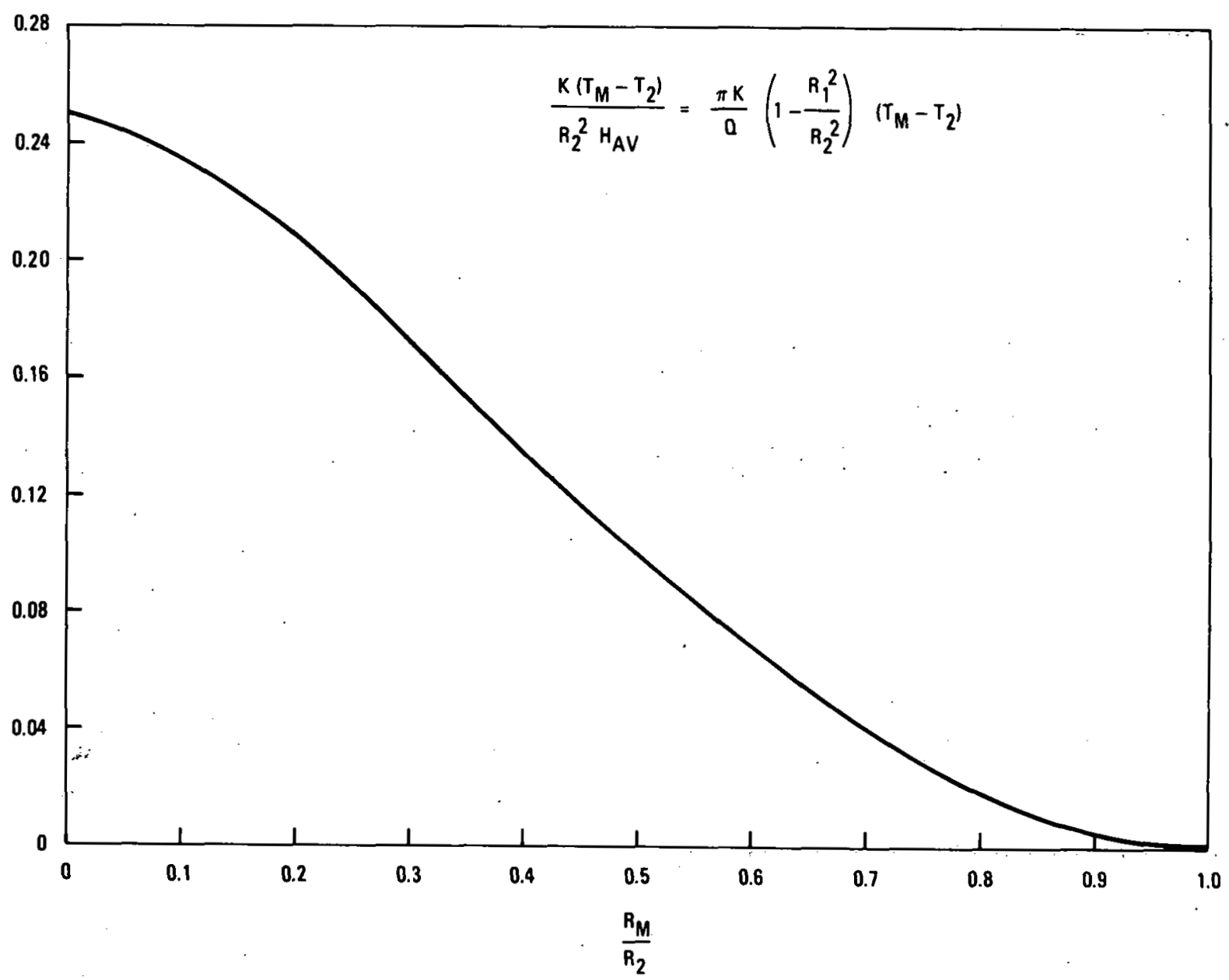

Fig. 18. Maximum temperature in a cylindrical shell when walls are maintained at given temperatures, as a function of the location of the maximum. Case of uniform power density 


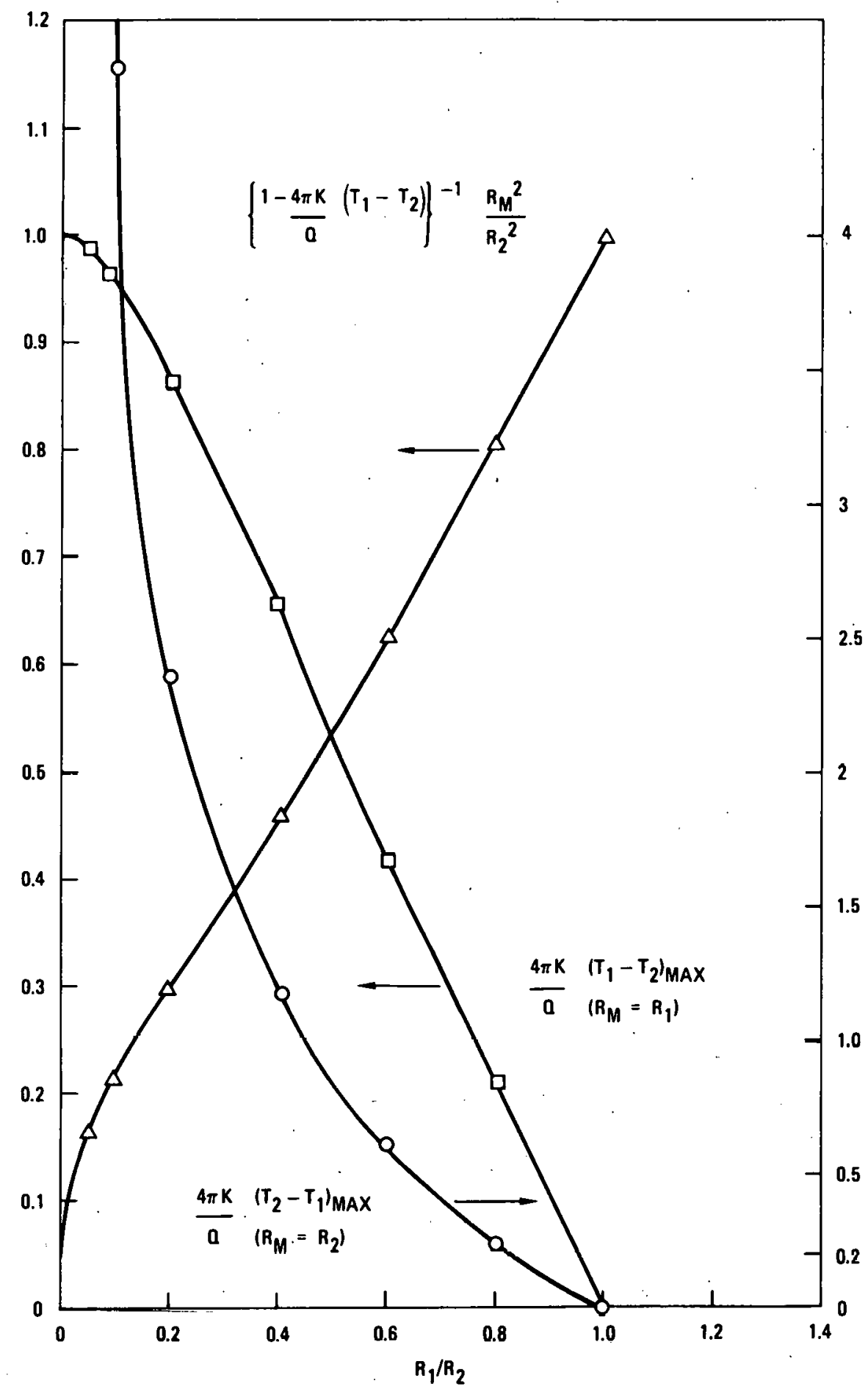

F1g. 19. Location of the maxlum fuel cemperature in a cylindrical shell cooled on both sides with uniform power density as a function of the ratio of diameters. 


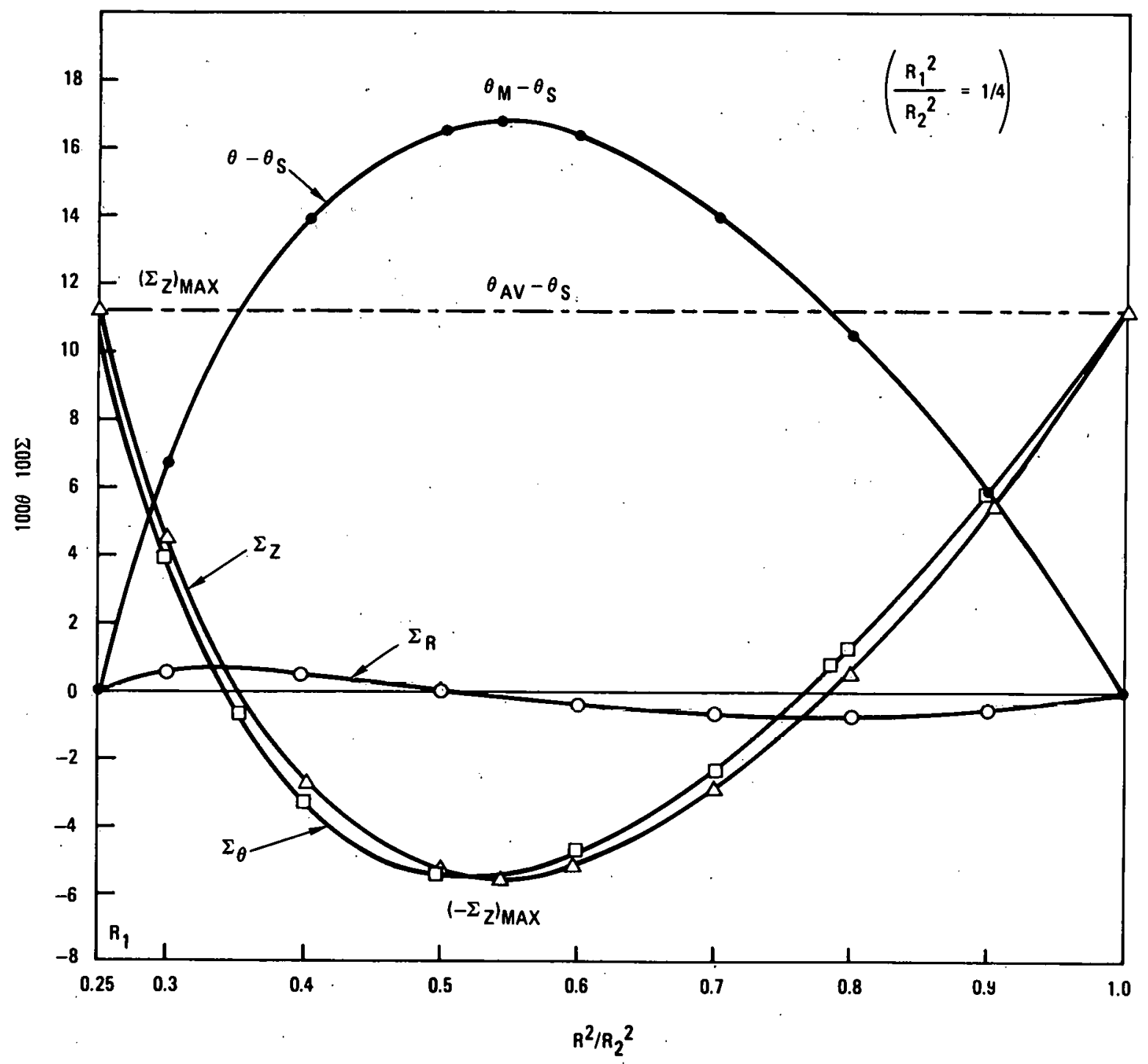

Fig. 20. Dimensionless temperature and stress distribution for uniform power density and equal surface temperatures 




Fig. 21. Ratio of maximum compressive axial and tangential stresses and location of these maximum stresses for uniform power density and equa - surface temperatures 


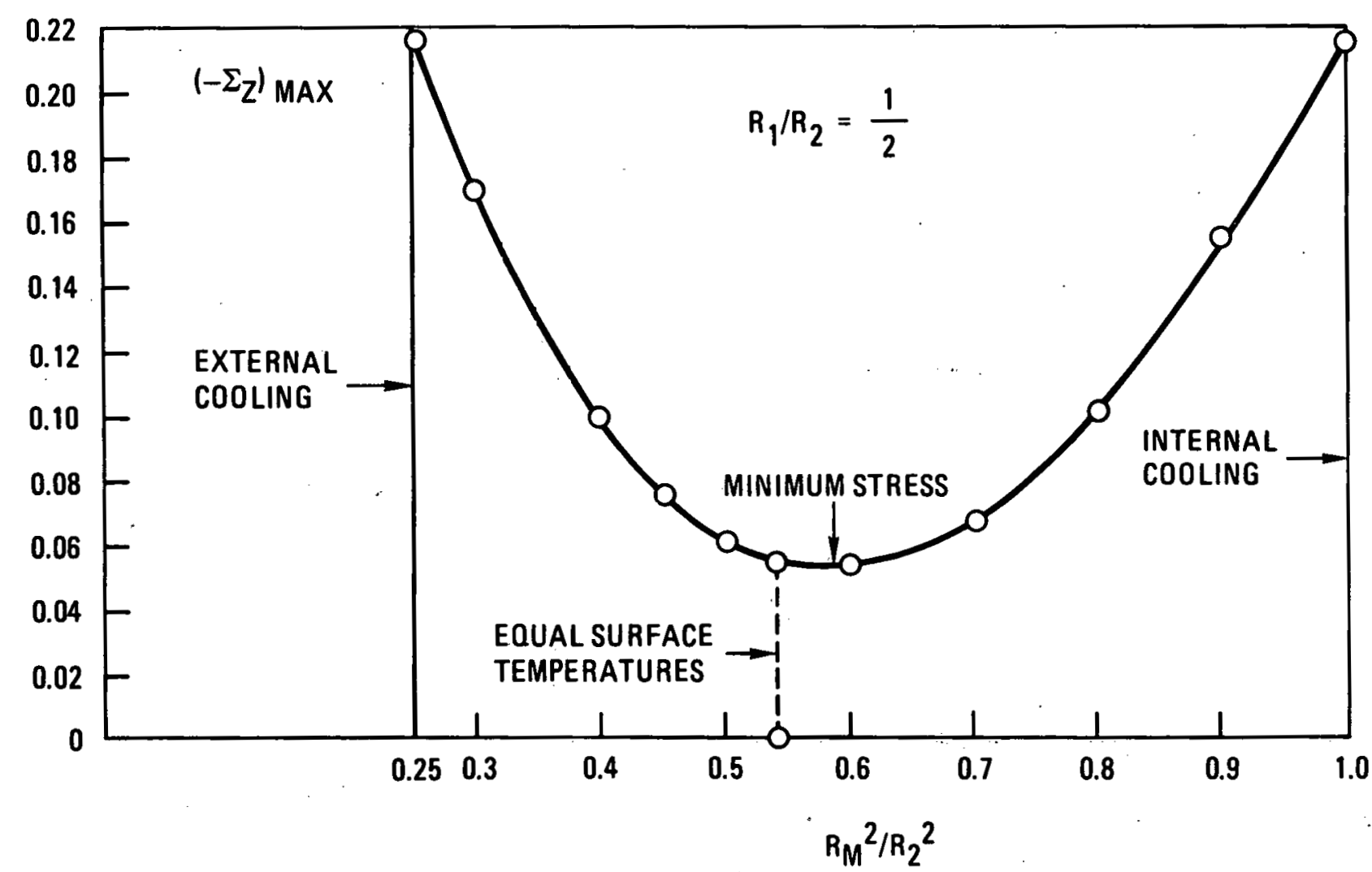

Fig. 22. Variation of maximum compressive stress with location of maximum fuel temperature for uniform power density 


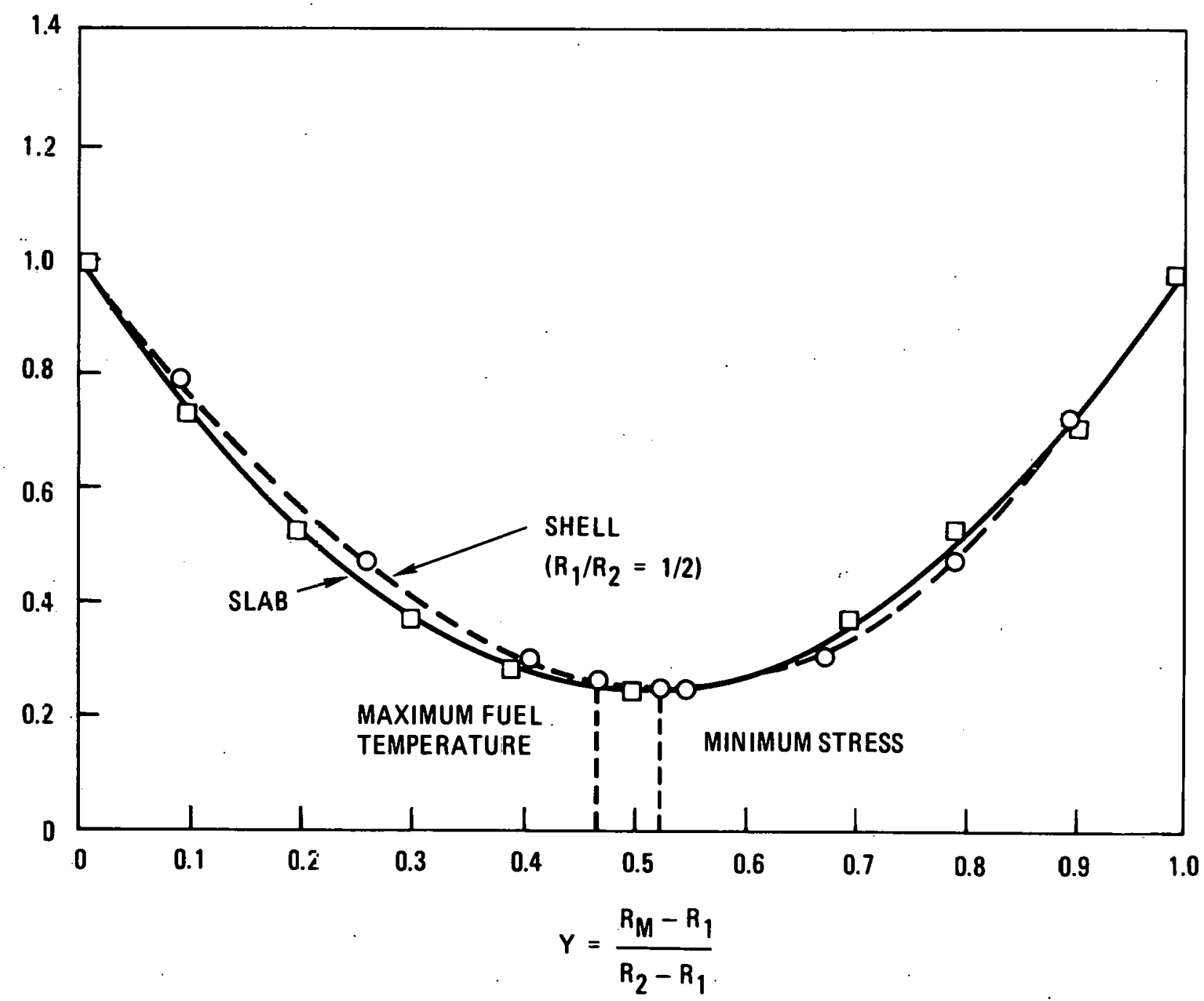

Fig. 23. Variations ú normalizzed maximum compressive stress (uniform power density) versus the Iocation of the maximum temperature 


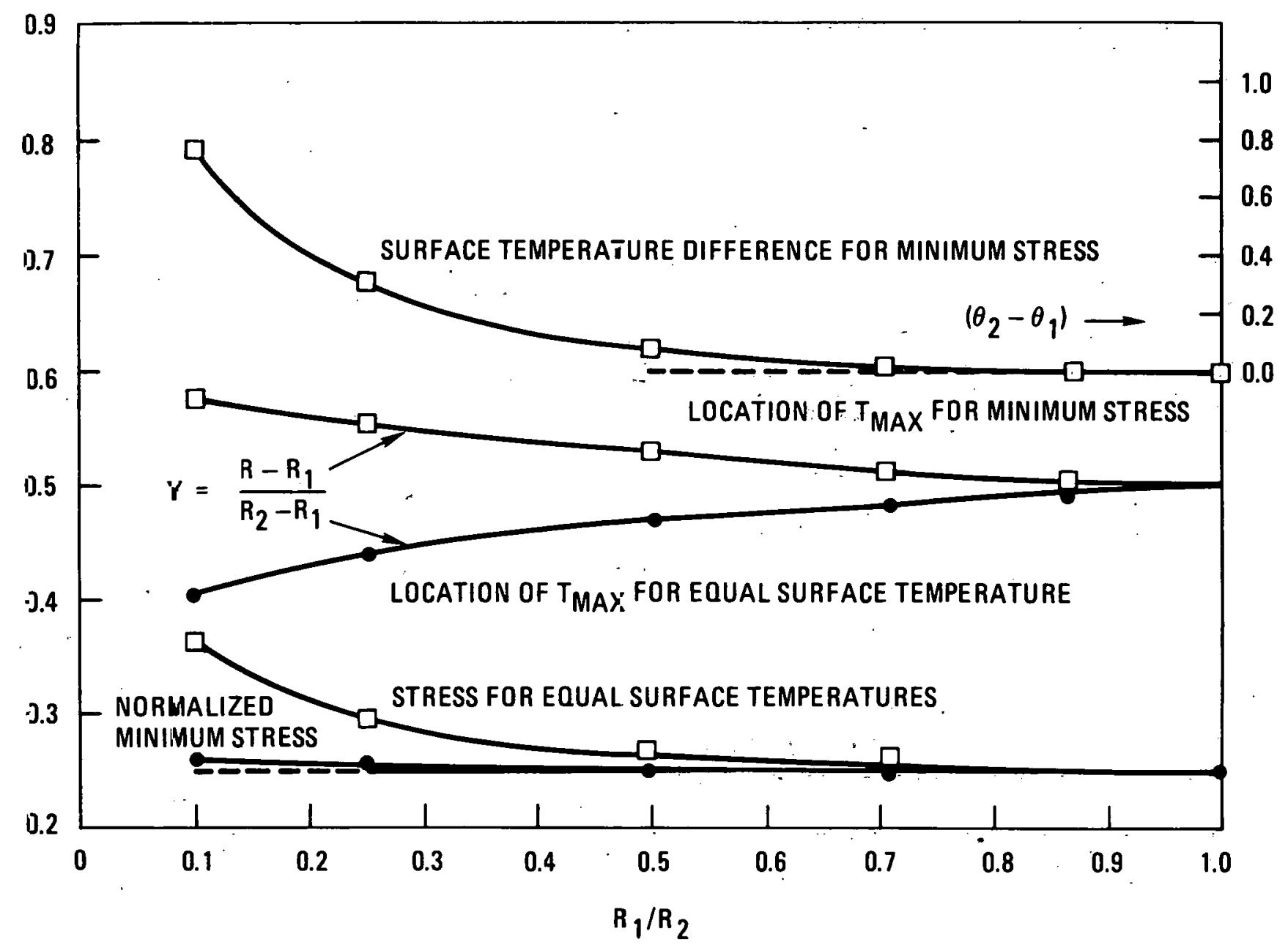

Fig. 24. Variations versus the geonetry of the normalized minimum value of the maximum compressive stress and relative location of this minimum for uniform power density 